\title{
Article \\ Functional States in Tumor-Initiating Cell Differentiation in Human Colorectal Cancer
}

\author{
Martina K. Zowada ${ }^{1,2,3,+} \mathbb{1}$, Stephan M. Tirier $4,5,6,+$, Sebastian M. Dieter $1,2,7,+$, Teresa G. Krieger ${ }^{4,5,8}$, \\ Ava Oberlack ${ }^{1}$, Robert Lorenz Chua 4,5,8 ${ }^{(\mathbb{D}}$, Mario Huerta ${ }^{1,2}$, Foo Wei Ten 4,5,8 ${ }^{\mathbb{D}}$, Karin Laaber 1,2,3 (D), \\ Jeongbin Park ${ }^{4,8}$, Katharina Jechow ${ }^{4,5,8}$, Torsten Müller ${ }^{9,10}$, Mathias Kalxdorf 9,10, Mark Kriegsmann ${ }^{11}$, \\ Katharina Kriegsmann ${ }^{12}$, Friederike Herbst ${ }^{1,2}{ }^{D}$, Jeroen Krijgsveld ${ }^{9,10}$, Martin Schneider ${ }^{13}$, Roland Eils ${ }^{4,5,8,14}$ \\ Hanno Glimm $1,2,15,16, *, \ddagger$, Christian Conrad $4,5,8, *, \ddagger$ (D) and Claudia R. Ball $1,2,15,16, *, \ddagger$ (D)
}

\section{check for} updates

Citation: Zowada, M.K.; Tirier, S.M. Dieter, S.M.; Krieger, T.G.; Oberlack, A.; Chua, R.L.; Huerta, M.; Ten, F.W.; Laaber, K.; Park, J.; et al. Functional States in Tumor-Initiating Cell Differentiation in Human Colorectal Cancer. Cancers 2021, 13, 1097. https: / doi.org/10.3390/cancers 13051097

Academic Editors: Marta Baiocchi and Ann Zeuner

Received: 12 February 2021 Accepted: 28 February 2021

Published: 4 March 2021

Publisher's Note: MDPI stays neutral with regard to jurisdictional claims in published maps and institutional affiliations.

Copyright: (c) 2021 by the authors. Licensee MDPI, Basel, Switzerland. This article is an open access article distributed under the terms and conditions of the Creative Commons Attribution (CC BY) license (https:// creativecommons.org/licenses/by/ $4.0 /)$.
1 Translational Functional Cancer Genomics, National Center for Tumor Diseases (NCT) Heidelberg and German Cancer Research Center (DKFZ) Heidelberg, 69120 Heidelberg, Germany; martina.zowada@nct-heidelberg.de (M.K.Z.); sebastian.dieter@nct-heidelberg.de (S.M.D.); ava.oberlack@med.uni-muenchen.de (A.O.); mario.huerta@nct-heidelberg.de (M.H.); karin.laaber@nct-heidelberg.de (K.L.); friederike.herbst@nct-heidelberg.de (F.H.)

2 Department of Translational Medical Oncology, NCT Dresden and DKFZ, 01307 Dresden, Germany

3 Faculty of Biosciences, Heidelberg University, 69120 Heidelberg, Germany

4 Division of Theoretical Bioinformatics, DKFZ Heidelberg, 69120 Heidelberg, Germany; s.tirier@dkfz-heidelberg.de (S.M.T.); teresa.krieger@charite.de (T.G.K.); robert-lorenz.chua@charite.de (R.L.C.); foo-wei.ten@charite.de (F.W.T.); j.park@dkfz-heidelberg.de (J.P.); katharina.jechow@bihealth.de (K.J.); roland.eils@charite.de (R.E.)

5 Center for Quantitative Analysis of Molecular and Cellular Biosystems (BioQuant), Heidelberg University, 69120 Heidelberg, Germany

6 Division of Chromatin Networks, DKFZ Heidelberg, 69120 Heidelberg, Germany

7 German Cancer Consortium (DKTK), 69120 Heidelberg, Germany

8 Digital Health Center, Berlin Institute of Health (BIH) and Charité-Universitätsmedizin Berlin, 10117 Berlin, Germany

9 Division of Proteomics of Stem Cells and Cancer, DKFZ Heidelberg, 69120 Heidelberg, Germany; torsten.mueller@dkfz-heidelberg.de (T.M.); mathiaskalxdorf@gmail.com (M.K.); j.krijgsveld@dkfz-heidelberg.de (J.K.)

10 Medical Faculty, Heidelberg University, 69120 Heidelberg, Germany

11 Institute of Pathology, Heidelberg University Hospital, 69120 Heidelberg, Germany; Mark.Kriegsmann@med.uni-heidelberg.de

12 Department of Hematology, Oncology and Rheumatology, Heidelberg University Hospital, 69120 Heidelberg, Germany; Katharina.Kriegsmann@med.uni-heidelberg.de

13 Department of General, Visceral and Transplantation Surgery, Heidelberg University Hospital, 69120 Heidelberg, Germany; Martin.Schneider@med.uni-heidelberg.de

14 Department for Bioinformatics and Functional Genomics, Institute for Pharmacy and Molecular Biotechnology (IPMB), Heidelberg University, 69120 Heidelberg, Germany

15 Center for Personalized Oncology, University Hospital Carl Gustav Carus Dresden at Technische Universität (TU) Dresden, 01307 Dresden, Germany

16 DKTK, 01307 Dresden, Germany

* Correspondence: hanno.glimm@nct-dresden.de (H.G.); christian.conrad@bihealth.de (C.C.); claudia.ball@nct-dresden.de (C.R.B.); Tel.: +49-351-458-5540 (H.G.); +49-30-450-543-097 (C.C.); +49-351-458-5536 (C.R.B.)

+ Shared first authorship.

$\ddagger$ Shared last authorship.

Simple Summary: Different types of cells with tumor-initiating cell (TIC) activity contribute to colorectal cancer (CRC) progression and resistance to anti-cancer treatment. In this study, we aimed to understand whether different cell types exist within a patient-derived tumor culture, distinguishable by different patterns of their gene expression. By mRNA sequencing of patient-derived CRC cultures at the single-cell level, we defined expression programs that closely resemble differentiated cell populations of the normal intestine. Here, cell type-associated subpopulations showed differences in functional properties such as cell growth and energy metabolism. Subsequent functional analyses in vitro and in vivo demonstrated that metabolic states are linked to TIC activity in primary CRC 
cultures. We also show that TIC activity is dependent on oxidative phosphorylation, which may therefore represent a target for novel therapies.

Abstract: Intra-tumor heterogeneity of tumor-initiating cell (TIC) activity drives colorectal cancer (CRC) progression and therapy resistance. Here, we used single-cell RNA-sequencing of patientderived CRC models to decipher distinct cell subpopulations based on their transcriptional profiles. Cell type-specific expression modules of stem-like, transit amplifying-like, and differentiated CRC cells resemble differentiation states of normal intestinal epithelial cells. Strikingly, identified subpopulations differ in proliferative activity and metabolic state. In summary, we here show at single-cell resolution that transcriptional heterogeneity identifies functional states during TIC differentiation. Furthermore, identified expression signatures are linked to patient prognosis. Targeting transcriptional states associated to cancer cell differentiation might unravel novel vulnerabilities in human CRC.

Keywords: colorectal cancer; tumor-initiating cells; tumor heterogeneity; patient-derived cancer models; single-cell RNA-sequencing; tumor metabolism; transcriptional programs; tumor cell differentiation

\section{Introduction}

In many tumor entities, tumor formation and progression are driven by a cellular subfraction with tumor-initiating cell (TIC) activity [1-3]. In colorectal cancer (CRC), the TIC compartment is organized as a functional cellular hierarchy with extensively self-renewing long-term TICs driving serial tumor propagation in vivo. Long-term TICs generate highly proliferative, short-lived tumor transient-amplifying cells with limited or no self-renewal capacity giving rise to the bulk of post-mitotic tumor cells [4]. Remarkably, this functional heterogeneity within individual CRCs is not primarily driven by genetic events, suggesting that epigenetic or extrinsic factors contribute to functional cellular heterogeneity [5].

Lineage-tracing experiments demonstrate that in CRC the population of highly selfrenewing TICs expresses LGR5 and generates progeny differentiating towards mucosecretingand absorptive-like phenotypes [6]. Thus, CRCs harbor a subfraction of stem-like TICs and maintain a hierarchical organization reminiscent of the normal intestinal epithelium [7]. Moreover, a gene signature specific for intestinal stem cells has been suggested to predict disease relapse [8], indicating a potential clinical relevance of stem-like TICs for CRC patients. However, prospective validation in an independent cohort is still not available.

Recent evidence suggests that the epigenome of an individual CRC is already formed by the cell-of-origin. Methylation analyses demonstrate maintenance of the cell-of-origin differentiation state during tumor progression, and identified three CRC subclasses of intestinal crypt differentiation of the cell-of-origin. Importantly, patients with a stem-like methylation signature showed significantly reduced overall survival [9].

While the hierarchical organization of normal and malignant stem cell systems has previously been thought to be fixed and unidirectional, evidence for plasticity in these systems is accumulating [10-12]. Lineage-tracing experiments in CRC highlight that more differentiated cells can repopulate a free stem-like niche and acquire TIC activity upon ablation of the active stem-like population $[6,13,14]$. Similarly, pronounced plasticity drives pancreatic cancer by clonal succession of transient TIC activity [15].

Current understanding of TIC heterogeneity in CRC is mainly derived from serial syngeneic or xenogeneic transplantation models, where TICs have been retrospectively identified by interpreting the kinetics of genetically marked or pre-enriched bulk cells $[4,8,16-18]$. While this allowed deep insights into functional heterogeneity within tumors, such retrospective experimental strategies from bulk samples hamper direct assignment of transcriptional states in individual cells. 
To characterize molecular underpinnings of functional CRC intra-tumor heterogeneity at the single-cell level, we here asked whether distinct functional programs within individual cells from patient-derived CRC models can be assigned to specific cellular subpopulations.

\section{Results}

\subsection{Transcriptional Heterogeneity of Patient-Derived CRC Spheroid Cultures}

To assess whether heterogeneous transcriptional programs can be detected in CRC tumor spheroids at the single-cell level, we performed single-cell RNA-sequencing (scRNAseq) using a nanowell platform [19]. As patient-derived spheroid cultures contain purely tumor cells, thereby allowing to study tumor cell heterogeneity in high resolution, and recapitulate the histology of the original tumor after xenotransplantation into immunodeficient NOD.Cg-Prkdc $c^{\text {scid }}$ Il2 $r g$ tm1Wjl $/$ SzJ (NSG) mice [4], we sequenced 12 three-dimensional tumor spheroid cultures (P1-P12) derived from primary tumors ( $n=6$ patients) or metastases ( $n=6$ patients) of 12 different CRC patients. These patient tumors and derived spheroids cover known subtypes (microsatellite stable or microsatellite instable tumors) and driver mutations (loss of APC and/or TP53, activating mutations in KRAS; Table 1). On average, 389 cells (range: 141-736) were sequenced per patient, resulting in 4663 single-cell profiles with an average of more than 4000 detected genes per cell (Table 2).

Table 1. Patient overview. Patient-derived colorectal cancer spheroids (P1-P12), organoids (O1-O3), xenografts (X1, X2), and primary colorectal cancer samples (T1-T3) used for single-cell RNA-sequencing. $\mathrm{X}$ indicates mutation, - indicates wild type. f, female; m, male; met, metastasis; MS, microsatellite; MSI, microsatellite instable; MSS, microsatellite stable; N/A, not available.

\begin{tabular}{|c|c|c|c|c|c|c|c|c|}
\hline Patient & Sex & Origin & Site & Stage (UICC) & MS status & TP53 & $A P C$ & KRAS \\
\hline P1 & $\mathrm{m}$ & liver met & Rectum & IV & MSS & $x$ & $x$ & $x$ \\
\hline $\mathrm{P} 2$ & $\mathrm{~m}$ & lung met & Caecum & IV & MSS & $X$ & $X$ & $x$ \\
\hline P3 & $\mathrm{f}$ & liver met & Rectum & IV & MSS & $x$ & $x$ & $x$ \\
\hline $\mathrm{P} 4$ & $\mathrm{f}$ & liver met & Ascending colon & IV & MSI & $x$ & $x$ & $x$ \\
\hline P5 & $\mathrm{f}$ & primary & Transverse colon & IV & MSS & - & - & - \\
\hline P6 & $\mathrm{f}$ & primary & Caecum & IV & MSS & $x$ & - & - \\
\hline P7 & $\mathrm{m}$ & liver met & Sigmoid & IV & MSS & - & $x$ & $x$ \\
\hline P8 & $\mathrm{m}$ & liver met & Caecum & IV & MSS & $x$ & - & - \\
\hline P9 & $\mathrm{m}$ & primary & Rectum & IV & MSS & $X$ & - & $x$ \\
\hline P10 & $\mathrm{m}$ & primary & Sigmoid & IIIB & MSS & $\mathrm{N} / \mathrm{A}$ & $\mathrm{N} / \mathrm{A}$ & $\mathrm{N} / \mathrm{A}$ \\
\hline P11 & $\mathrm{m}$ & primary & Rectum and caecum & IIIB & MSS & - & - & - \\
\hline P12 & $\mathrm{m}$ & primary & $\begin{array}{l}\text { Rectum and transverse } \\
\text { colon }\end{array}$ & II & MSI & $x$ & $x$ & $x$ \\
\hline O1 & $\mathrm{f}$ & liver met & Sigmoid & IV & MSS & $x$ & $x$ & $x$ \\
\hline $\mathrm{O} 2$ & $\mathrm{f}$ & liver met & Caecum & IV & MSS & $X$ & $X$ & $x$ \\
\hline $\mathrm{O} 3$ & $\mathrm{f}$ & liver met & Ascending colon & IV & MSI & - & $x$ & - \\
\hline $\mathrm{X} 1$ & $\mathrm{~m}$ & primary & Rectum & $\mathrm{I}$ & $\mathrm{N} / \mathrm{A}$ & $\mathrm{N} / \mathrm{A}$ & $\mathrm{N} / \mathrm{A}$ & $\mathrm{N} / \mathrm{A}$ \\
\hline $\mathrm{X} 2$ & $\mathrm{~m}$ & primary & Ascending colon & II & MSI & $\mathrm{N} / \mathrm{A}$ & $\mathrm{N} / \mathrm{A}$ & - \\
\hline $\mathrm{T} 1$ & $\mathrm{~m}$ & primary & Sigmoid & III & $\mathrm{N} / \mathrm{A}$ & $\mathrm{N} / \mathrm{A}$ & $\mathrm{N} / \mathrm{A}$ & $\mathrm{N} / \mathrm{A}$ \\
\hline $\mathrm{T} 2$ & $\mathrm{~m}$ & primary & Ascending colon & IV & $\mathrm{N} / \mathrm{A}$ & $\mathrm{N} / \mathrm{A}$ & $\mathrm{N} / \mathrm{A}$ & $\mathrm{N} / \mathrm{A}$ \\
\hline T3 & $\mathrm{m}$ & primary & Ascending colon & IVa & MSS & $\mathrm{N} / \mathrm{A}$ & $\mathrm{N} / \mathrm{A}$ & X \\
\hline
\end{tabular}


Table 2. Single-cell RNA-sequencing analysis. Top: Colorectal cancer (CRC) spheroids (P1-P12). Cultures with an LGR5 score (=LGR5 read counts/cell number) $>1$ are considered $L G R 5^{+}$. Bottom: patient-derived organoids (PDOs; O1-O3), patient-derived xenografts (PDXs; X1, X2), and tumors (T1-T3). Cell numbers for X1 and X2 indicate human cells. Cell numbers in brackets indicate epithelial cells used for analysis of T1-T3. Hs, Homo sapiens; Mm, Mus musculus; QC, quality control.

\begin{tabular}{|c|c|c|c|c|}
\hline \multicolumn{5}{|c|}{ CRC Spheroids } \\
\hline Patient & Mean Reads Per Cell & Cell Number after QC & $\begin{array}{c}\text { Mean Detected Genes } \\
\text { Per Cell }\end{array}$ & LGR5 Score \\
\hline P1 & 348,016 & 325 & 3535 & 12.85 \\
\hline $\mathrm{P} 2$ & 261,595 & 309 & 4072 & 0.23 \\
\hline P3 & 460,471 & 551 & 4537 & 6.43 \\
\hline $\mathrm{P} 4$ & $1,061,813$ & 263 & 4186 & 87.72 \\
\hline P5 & 334,099 & 502 & 3943 & 4.61 \\
\hline P6 & $1,276,856$ & 141 & 5116 & 0.03 \\
\hline P7 & 359,362 & 434 & 4335 & 10.18 \\
\hline P8 & 190,170 & 197 & 4174 & 3.38 \\
\hline P9 & 527,407 & 464 & 4354 & 0.00 \\
\hline P10 & 391,680 & 736 & 3418 & 3.35 \\
\hline P11 & 505,439 & 308 & 4036 & 1.43 \\
\hline P12 & 454,258 & 433 & 3977 & 0.00 \\
\hline \multicolumn{5}{|c|}{ CRC PDOs, PDXs, Tumors } \\
\hline Sample & Mean Reads Per Cell & Cell Number after QC & $\begin{array}{l}\text { Mean Detected Genes } \\
\text { Per Cell }(H s)\end{array}$ & $\begin{array}{l}\text { Mean Detected Genes } \\
\text { Per Cell }(M m)\end{array}$ \\
\hline O1 & 120,218 & 5550 & 5542 & - \\
\hline $\mathrm{O} 2$ & 169,086 & 3003 & 5425 & - \\
\hline $\mathrm{O} 3$ & 73,415 & 8785 & 4176 & - \\
\hline $\mathrm{X} 1$ & 238,836 & 1475 & 1841 & 2281 \\
\hline $\mathrm{X} 2$ & 237,891 & 1070 & 4598 & 2415 \\
\hline $\mathrm{T} 1$ & $1,333,884$ & $362(136)$ & 3646 & - \\
\hline $\mathrm{T} 2$ & 847,472 & $538(77)$ & 4090 & - \\
\hline $\mathrm{T} 3$ & 623,942 & $724(40)$ & 2474 & - \\
\hline
\end{tabular}

Unsupervised clustering of single-cell profiles [20] revealed grouping of cells according to the patient-of-origin (Figure 1a). Hierarchical clustering based on the top 10 differentially expressed genes per patient showed that cells primarily cluster, with one exception, by the tumor site they originate from, but not by microsatellite status (Figure 1a,b).

Within individual patient-derived spheroids, top differentially expressed genes (Wilcoxon rank sum test: adjusted $p$-value $<0.05$; log fold-change $>0.25$ ) between patients contained WNT signaling components and downstream targets (e.g., FRZB, DKK1, TCF4, SOX2) and normal tissue-associated differentiation markers (e.g., MUC12, MUC17, SPINK1, SPINK4, DEFA5, DEFA6; Figure 1b). Thus, beyond patient tumor-specific alterations, differentiation state-associated expression programs can be attributed to transcriptional profiles derived from single CRC cells. 
(a)

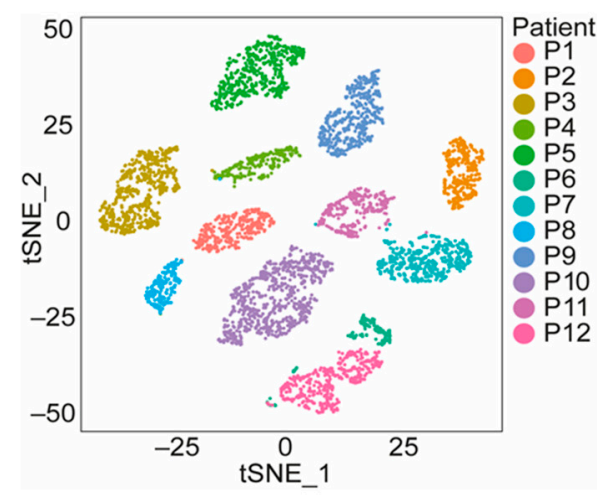

(c)

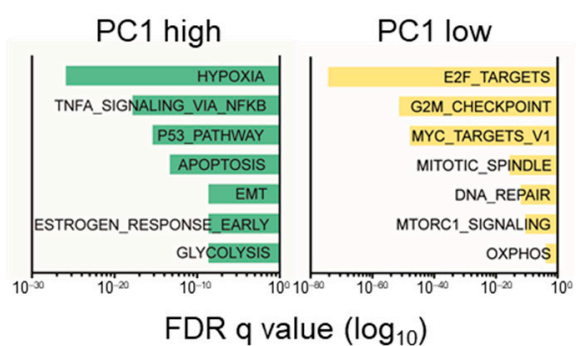

(b)
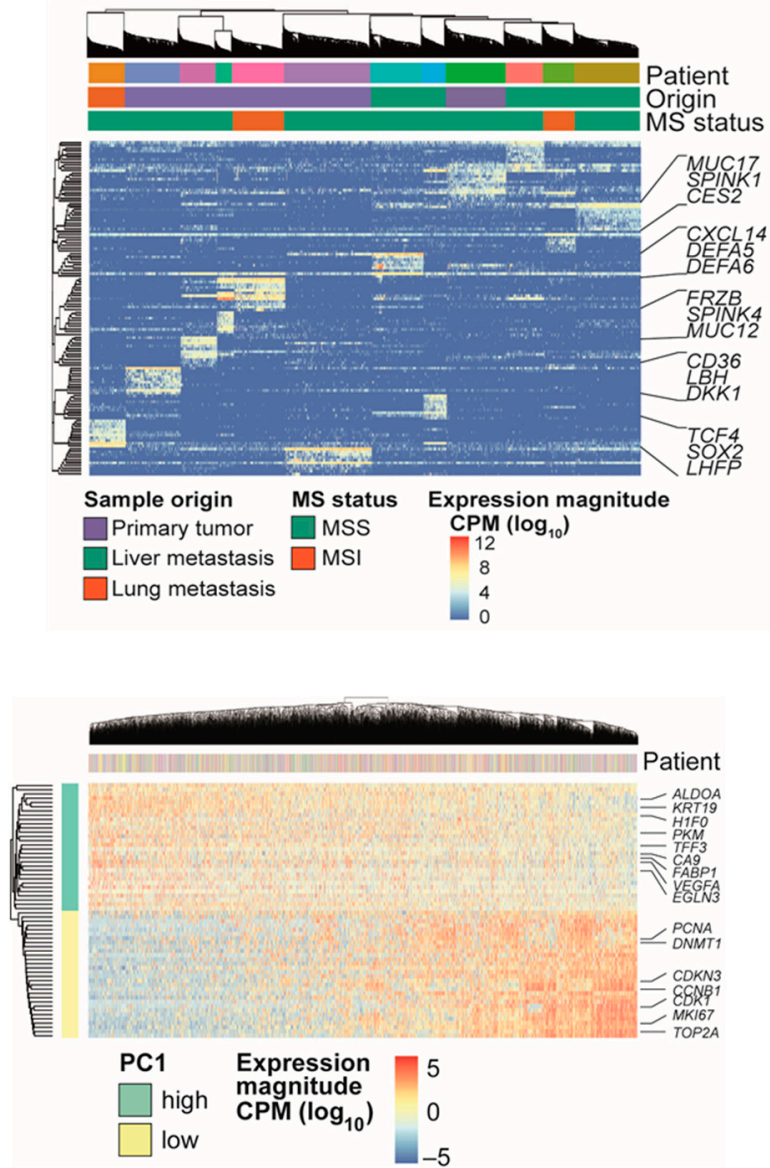

(d)

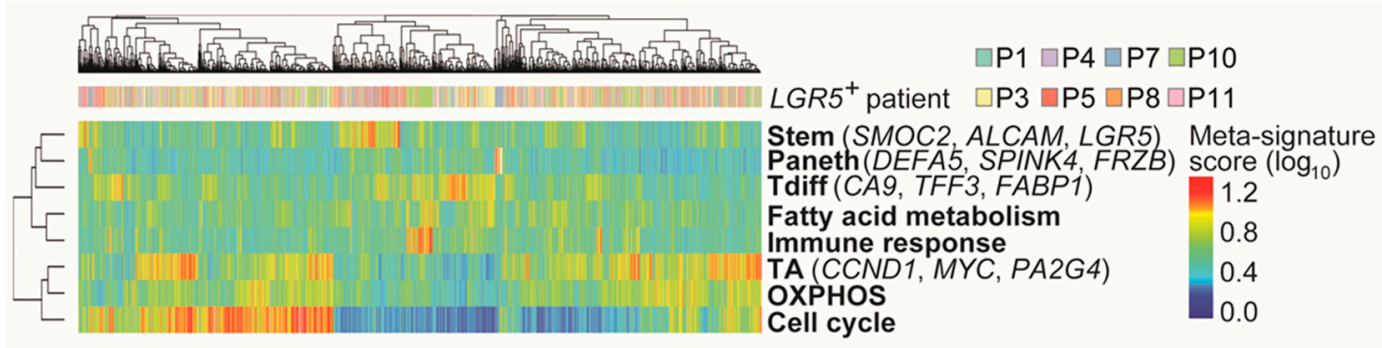

Figure 1. Identification of transcriptional subpopulations by single-cell RNA-sequencing (scRNA-seq). (a) Two-dimensional $\mathrm{t}$-distributed stochastic neighbor embedding ( $\mathrm{tSNE}$ ) visualization of scRNA-seq expression profiles. (b) Hierarchical clustering and heatmap visualization of single-cell gene expression using the top 10 differentially expressed genes per patient $(n=12)$. CPM, counts-per-million; MS, microsatellite; MSI, microsatellite instable; MSS, microsatellite stable. (c) Principal component analysis of scRNA-seq data corrected for inter-patient variability. Left: Gene set enrichment analysis (GSEA) for the first principal component (PC1; hallmark gene sets). Gene sets are ranked by false discovery rate (FDR) $\mathrm{q}$ values. Right: Heatmap showing gene expression magnitude of the top 30 genes with highest and lowest PC scores for PC1. OXPHOS, oxidative phosphorylation. (d) Heatmap reflecting hierarchical clustering of core meta-signature scores of eight $L G R 5^{+}$CRC spheroid cultures determined by non-negative matrix factorization. Brackets indicate marker genes for specific signatures. TA, transit-amplifying; Tdiff, terminally differentiated.

\subsection{Distinct Cell Types and Cell States in Individual CRC Spheroids}

To identify heterogeneous gene expression programs shared across patients in single cells from individual tumor spheroid cultures, we corrected for inter-patient variability by calculating relative expression levels for each patient individually [21,22]. Principal com- 
ponent analysis (PCA) of the combined dataset revealed an anti-correlated transcriptional pattern independent of patient origin with genes either involved in cell growth, proliferation, and oxidative phosphorylation (OXPHOS), or hypoxia and glycolysis. Notably, the hypoxia/glycolysis signature contains intestinal differentiation markers (e.g., TFF3, FABP1, KRT19; Figure 1c), indicating an association of distinct metabolic states with tumor cell differentiation and proliferation, as recently described for the normal intestinal crypt [23].

As the activation of continuous gene expression programs may not be captured by discrete clustering, we adapted a previously described computational approach based on non-negative matrix factorization (NNMF) $[24,25]$ to more precisely identify transcriptional programs heterogeneously expressed across patients (Figure 1d, Figure S1a-e). In order to focus on tumors that display preserved hierarchical organization, we focused on the eight cultures with detectable LGR5 transcript levels (LGR5 score = total LGR5 transcript counts / cell number > 1; Table 2), as LGR5 represents an established marker for intestinal stem cells and CRC TICs, whereas the phenotype and the role of potential LGR5-negative stem cells and TICs are much less defined $[8,14,26,27]$. Thus, four cultures with very low or non-detectable $L G R 5$ transcript abundance were excluded for this analysis. We identified 13 heterogeneous gene expression programs that could be classified into two partially overlapping categories: one (A) linked to 'cell types' or lineages analogous to the normal intestinal epithelium, and the other (B) associated with 'cell states' (Figure S1f).

Category A identified distinct cells harboring marker expression similarities to normal intestinal stem cells (e.g., LGR5, AXIN2), Paneth cells (e.g., DEFA5, DEFA6), or transitamplifying (TA) cells (e.g., PA2G4, CCND1) in the healthy human intestine, suggesting that distinct cell types can be identified based on individual gene expression programs. As the analyzed cells derive from the colon and only resemble the cell types of the normal intestine, we refer to these cell type-associated subpopulations as stem-like, Paneth-like, TA-like, and terminally differentiated (Tdiff)-like. Category B comprised expression programs enriched for genes involved in cell cycle regulation (e.g., CDK1, MKI67), immune/stress response (e.g., CEACAM6, CXCL2), or metabolic functions (e.g., OXPHOS (e.g., PRDX3, $A T P 5 O$ ), fatty acid metabolism (e.g., CES2, RETSAT), and hypoxia/glycolysis (e.g., HILPDA, $V E G F A)$ ). Similar to PCA results (Figure 1c), one expression program (Tdiff) was enriched for both, genes associated with hypoxia/glycolysis and differentiation markers (e.g., TFF3, KRT20; Figure S1f).

Next, each individual cell was scored for inferred expression programs using the averaged expression of the top genes per factor identified by NNMF. To reduce redundancy, signatures showing similar enrichment and clustering patterns were combined, resulting in eight meta-signatures (Figure S1a-f, Table S1). Clustering of meta-signature scores allowed identification of discrete and overlapping transcriptional programs (Figure 1d). Similar to PCA, cell cycle, OXPHOS, and TA signatures showed a pronounced overlap, indicating a highly proliferative cell fraction-potentially corresponding to the TA-like compartment-driven by MYC and characterized by high OXPHOS. In contrast, stemlike, Paneth-like, and Tdiff-like cells did not show significant overlap with the cell cycle signature (Figure 1d), suggesting reduced or absent proliferative activity. This indicates that scRNA-seq and matrix factorization analysis are capable of distinguishing functionally distinct cell populations based on transcriptional profiles.

To analyze the cell type composition in all eight $L G R 5^{+}$cultures individually, we used the NNMF-inferred signature scores (stem, TA, Paneth, Tdiff) to assign cells to one of the four cell types which allowed us to assess the extent of active cell type-specific transcriptional programs. Despite different cell type compositions, we observed presence of stem-like, TA-like, and Tdiff-like cells in all, and rare, but detectable Paneth-like cells in six out of the eight $L G R 5^{+}$cultures (Figure S1g). This indicates that individual CRC tumors display similar cellular diversity resembling normal intestinal cell types even with different clinico-pathological features (Table 1).

We next assessed whether the signatures identified in our patient-derived in vitro models can also be identified in patient tumors. We therefore applied our signatures 
(Table S1) on publicly available expression data of colon adenocarcinoma (COAD) patients (The Cancer Genome Atlas (TCGA) cohort; $n=328$ patients) [28]. Correlations among cell type and cell state signatures in the spheroid scRNA-seq data (Figure 1d) were detectable in patient whole transcriptome data. Clustering of the TCGA cohort based on signature expression resulted in six clusters of patients (cl1-cl6) with different combinations of low or high expression of individual signatures. Significantly different progression-free survival $(p=0.043)$ and numerically decreased overall survival $(p=0.059)$ were observed between groups of clusters, indicating a relevance of signature expression for patient prognosis (Figure 2a-c, Table S2).

We further compared the association of cl1-cl6 with consensus molecular subtypes (CMS1-CMS4) $[29,30]$. CMS1 tumors were mostly represented in cl3 (49\%), CMS2 tumors displayed mostly cl2 (37\%) and cl4 (24\%), CMS3 tumors were predominantly found in cl1 (36\%). CMS4 tumors were spread across cl4 (14\%), cl5 (43\%), and cl6 (20\%). CMS4 has been shown to have poor progression-free survival [30]. Accordingly, cl4, cl5, and cl6 (33\%, 60\%, and $65 \%$ CMS4 contribution, respectively) showed the worst progression-free survival. cl6 comprised the majority of patients with the shortest overall survival of CMS4, whereas cl4 displayed worse progression-free survival than $\mathrm{cl} 1, \mathrm{cl} 2$, and $\mathrm{cl} 3$ but similar overall survival (Figure 2c,d).

In line with previously published data reporting an intestinal stem cell-specific gene signature linked to LGR5 and EPHB2 expression related to CRC relapse [8], high expression of our stem signature defined by 200 genes (Table S1) in the TCGA cohort displayed decreased progression-free survival $(p=0.068)$ compared to patients with low expression (Figure 2e).

Taken together, our six clusters exhibit a better prognostic value for progressionfree survival $(p=0.043)$ than previously reported subtypes linked to cancer-associated fibroblasts [31] ( $p=0.15)$, CMSs [29,30] ( $p=0.18)$, or our stem signature alone $(p=0.068)$. Indeed, when our clusters were added to multivariable clinico-molecular survival models, we still observed a significant discriminative contribution by our cluster combinations in predicting recurrence, but no significant contribution was appreciated when adding CMSs or cancer-associated fibroblasts to our model. On the other hand, incorporating stroma cells like cancer-associated fibroblasts can substantially improve the overall survival prediction (Table S2). These results underscore the relevance of combinations of cell type and cell state signature expression for COAD outcome, and demonstrate a prognostic value of cell type and cell state signatures inferred from spheroid single-cell transcriptomes. 
(a)
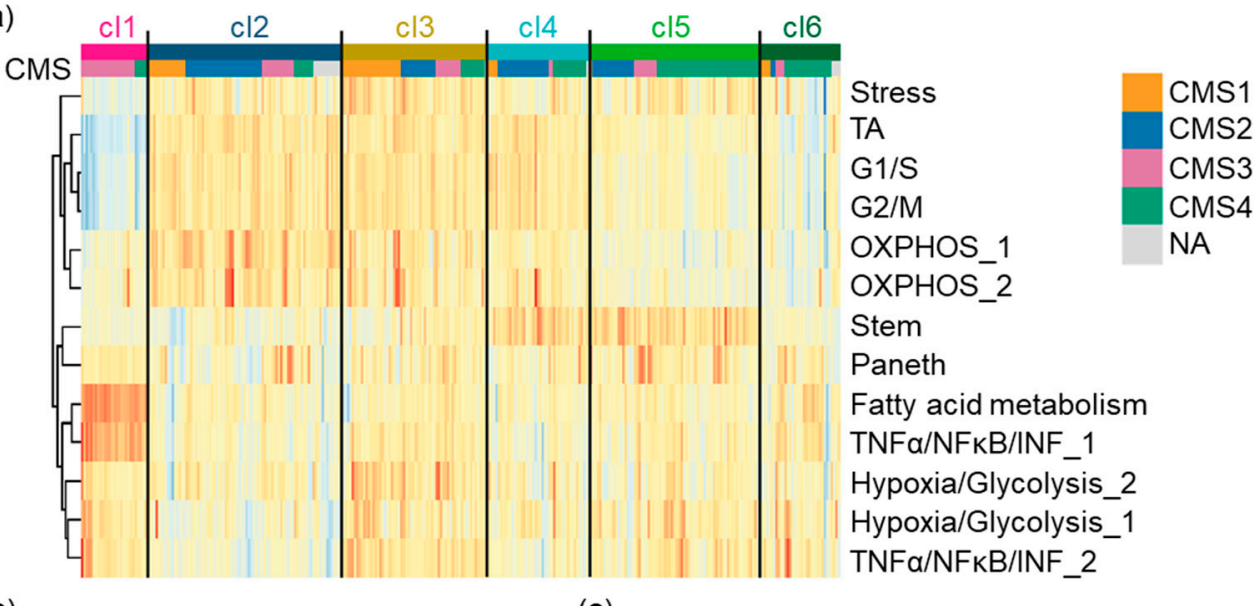

(b)

\begin{tabular}{|l|c|c|c|c|c|c|}
\hline & $\mathrm{cl} 1$ & $\mathrm{cl} 2$ & $\mathrm{cl} 3$ & $\mathrm{cl} 4$ & $\mathrm{cl} 5$ & $\mathrm{cl6}$ \\
\hline Proliferation & - & + & + & + & - & - \\
\hline OXPHOS_1 & - & + & + & - & - & - \\
\hline Stem & - & & & + & + & - \\
\hline Paneth & + & & & & & \\
\hline Fatty acid & + & & & & & - \\
\hline TNFa_1 & + & & & & & - \\
\hline Hyp/Glycolysis & & & + & & & \\
\hline TNFa_2 & & - & + & & & \\
\hline
\end{tabular}

(c)

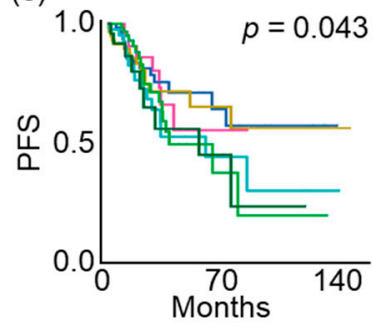

CMS1

CMS2

CMS4

NA

OXPHOS_2

Stem

Paneth

Fatty acid metabolism

TNFa/NFKB/INF_1

Hypoxia/Glycolysis_2

Hypoxia/Glycolysis_1

TNFa/NFKB/INF_2

cl1 cl2 cl3 cl4 cl5 cl6

(d)

cl1 $\mathrm{cl} 2 \mathrm{cl} 3 \mathrm{cl} 4 \mathrm{cl} 5 \mathrm{cl} 6$

Patients [\%] (29) (71) (62) (43) (73) (31)

\begin{tabular}{c|c|c|c|c|c|c|} 
CMS1 (53) & 0 & 16 & 26 & 5 & 1 & 5 \\
\cline { 2 - 8 } CMS2 (90) & 0 & 33 & 15 & 22 & 18 & 2 \\
\cline { 2 - 7 } CMS3 (64) & 23 & 14 & 11 & 2 & 10 & 4 \\
\hline CMS4 (102) & 6 & 8 & 10 & 14 & 44 & 20 \\
\hline & & & & & &
\end{tabular}
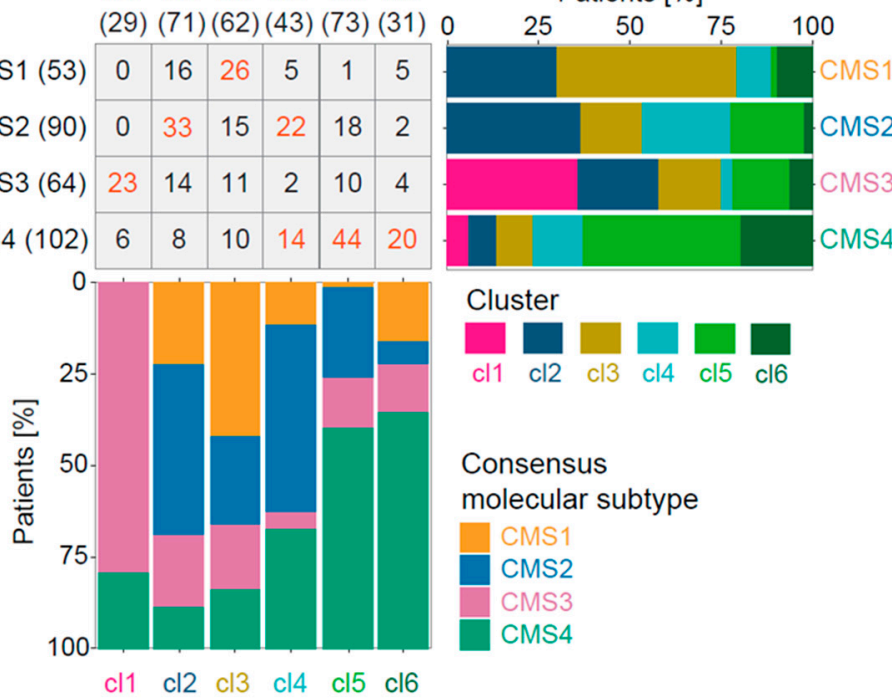

(e)

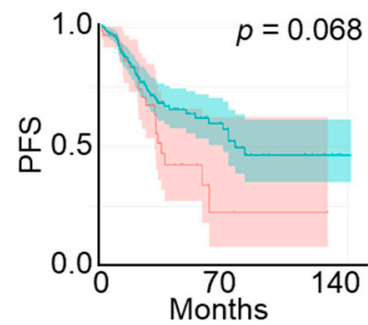

Cluster
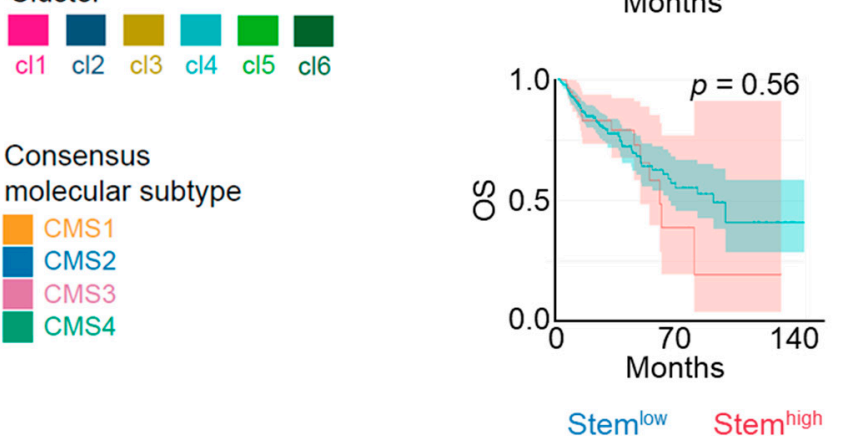

Figure 2. Analysis of single-cell RNA-sequencing (scRNA-seq) signature expression in The Cancer Genome Atlas (TCGA) colon adenocarcinoma (COAD) cohort. (a) Heatmap reflecting signature expression in the identified clusters of patients (cl1-cl6). Rows correspond to scRNA-seq signatures $(n=13)$. Columns correspond to TCGA COAD samples $(n=328)$. Clusters are further classified according to consensus molecular subtypes (CMS1-CMS4). NA, not assigned; OXPHOS, oxidative phosphorylation; TA, transit-amplifying. (b) Cell type and cell state signature expression levels defining cl1-cl6. Hyp, hypoxia. (c) Kaplan-Meier survival curves displaying progression-free survival (PFS) and overall survival (OS) for cl1-cl6. $p$-Values of the comparison $\mathrm{cl} 6+\mathrm{cl} 5+\mathrm{cl} 4$ versus $\mathrm{cl} 3+\mathrm{cl} 2+\mathrm{cl} 1$ for PFS and $\mathrm{cl} 6+\mathrm{cl} 5$ versus $\mathrm{cl} 4+\mathrm{cl} 3+\mathrm{cl} 2+\mathrm{cl} 1$ for OS (d) Representation of CMS1-CMS4 within cl1-cl6 and of cl1-cl6 within CMS1-CMS4. Numbers indicate amount of patients classified under individual categories. Numbers marked in red highlight dominant combinations. Patients not assigned to a CMS ( $n=19$ patients) were excluded. (e) PFS and OS of TCGA COAD patients with high versus low expression of the stem signature. Shaded areas indicate $95 \%$ confidence intervals. 


\subsection{Cell Cycle and Proliferative Activity of Human CRC Cells}

scRNA-seq suggests the existence of cell types with different proliferative activity within individual spheroid cultures and stem-like, TA-like, and Tdiff-like subpopulations. We therefore asked whether subfractions of cells with different cell cycle and proliferative activity exist within CRC tumors in vivo and whether they are functionally relevant.

To assess proliferative heterogeneity of tumor cells, we utilized a genetic labelretaining strategy based on expression of tetracycline-regulated (Tet-off) histone 2B (H2B) green fluorescent protein (GFP) [32] (Figure S2a). Upon doxycycline addition, nuclear H2BGFP expression is suppressed and subsequently diluted with each cell division, allowing identification of subpopulations according to proliferative history.

To evaluate whether proliferatively inactive cells within established tumors possess TIC capacity, we transduced tumor spheroid cultures derived from seven different patients with an H2B-GFP-encoding lentiviral vector prior to xenotransplantation into NSG mice ( $n=14 ; 1-4$ mice per culture). After successful tumor formation, H2B-GFP expression was suppressed by doxycycline administration for two weeks. Analysis of H2B-GFP expression in established tumors by flow cytometry revealed presence of fast $\left(\mathrm{GFP}^{-}\right)$, slow (GFPlow), and rare dividing (GFPhigh) cell fractions, demonstrating proliferative heterogeneity of CRC cells in vivo. To assess whether heterogeneously proliferating cell fractions are associated with TIC activity, cells from 12 out of 14 primary xenografts were sorted into fast, slow, and rare dividing subfractions and serially transplanted into secondary mice $(n=33)$. Importantly, all subfractions contained cells with TIC activity irrespective of transplanted cells' proliferative history prior to re-transplantation (fast: $5 / 12$; slow: 4/9; rare: $5 / 12$ mice with tumors), showing that TIC activity is not strictly linked to proliferative active cell fractions but also present in proliferatively inactive populations within tumors (Figure S2a-c). In summary, these data show that proliferatively inactive TICs exist within established tumors in vivo. We therefore conclude that within individual tumors, TIC activity can be present in cells with heterogeneous proliferative activity and is therefore not restricted to a specific proliferative state of individual cells.

\subsection{Divergent Cell Type-Associated Energy Metabolic Preferences}

Prominent heterogeneously expressed transcriptional programs in individual spheroid cells were related to energy metabolism. Whereas a glycolysis/hypoxia signature could be assigned to Tdiff-like cells (Figure S1f), OXPHOS strongly overlapped with MYC-target and cell cycle signatures, both identifying cells belonging to the putative TA-like cell compartment (Figure 1c,d). Thus, we hypothesized that metabolic preferences distinguish functionally distinct cell subpopulations and focused on these for further validation.

Consistently, we observed clearly overlapping TA-like, OXPHOS, and cell cycle signatures (Figure 1d), but no obvious association between stem-like and OXPHOS or cell cycle signatures. Of note, in the normal intestinal epithelium, intestinal stem cells actively cycle and constantly produce progeny, but their relative abundance compared to non-cycling Tdiff cells is very low [33]. Thus, we reasoned that differential metabolic trends in stem-like and Paneth-like cells could be masked by much higher or lower expression of individual metabolic signatures in highly cycling cells or the rare dividing Tdiff-like subpopulation. To overcome this, we performed pairwise comparisons of cell state signatures across CRC subpopulations that resemble normal intestinal cell types as identified by differential NNMF signature expression.

Cell cycle scores were strongly increased in TA-like cells compared to stem-like, Paneth-like, and Tdiff-like cells ( $p<0.000001$; respectively). The greatest differences in metabolic states existed between Tdiff-like and TA-like subpopulations, demonstrating that the majority of TA-like cells had high OXPHOS scores, whereas Tdiff-like cells showed high scores for hypoxia and glycolysis, but low scores for OXPHOS. Albeit less pronounced, similar and highly significant differences were detectable for stem-like and Paneth-like cells. In comparison to Paneth-like cells, stem-like cells showed increased OXPHOS scores and decreased glycolysis/hypoxia scores ( $p<0.000001$, respectively; Figure 3a). 
In addition to the overall high OXPHOS scores, the stem-like signature was associated with enhanced expression of OXR1 and PON2. Being essential for protection against oxidative stress, these genes may counteract higher reactive oxygen species (ROS) levels resulting from enhanced OXPHOS rates [34,35]. Another gene included in the stem-like signature is MAP2K6 - an essential p38 signaling component [36] known to be associated with high OXPHOS levels in intestinal stem cells [23] (Figure S1f, Table S1).

Collectively, these results demonstrate an association between tumor cell differentiation and metabolic identities in this three-dimensional in vitro CRC model. 
(a) Spheroids
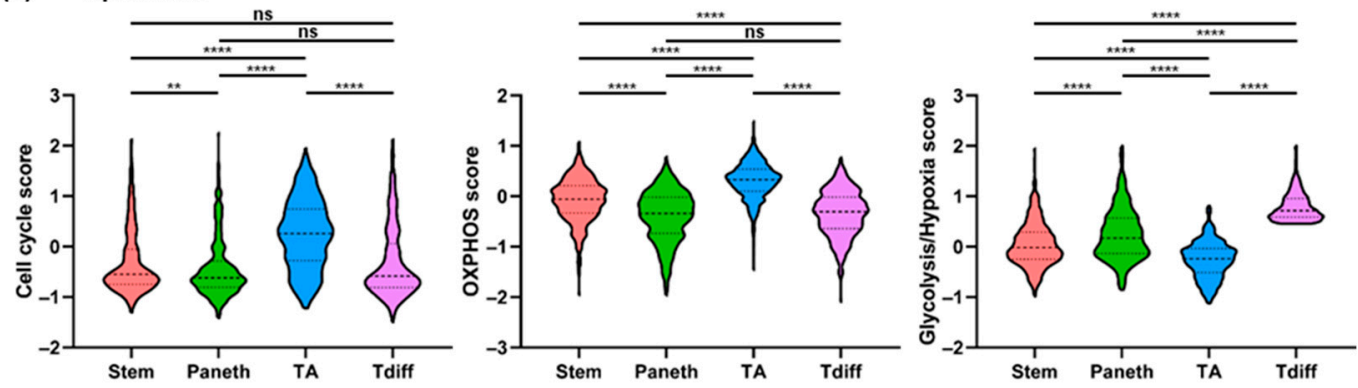

(b)

PDO
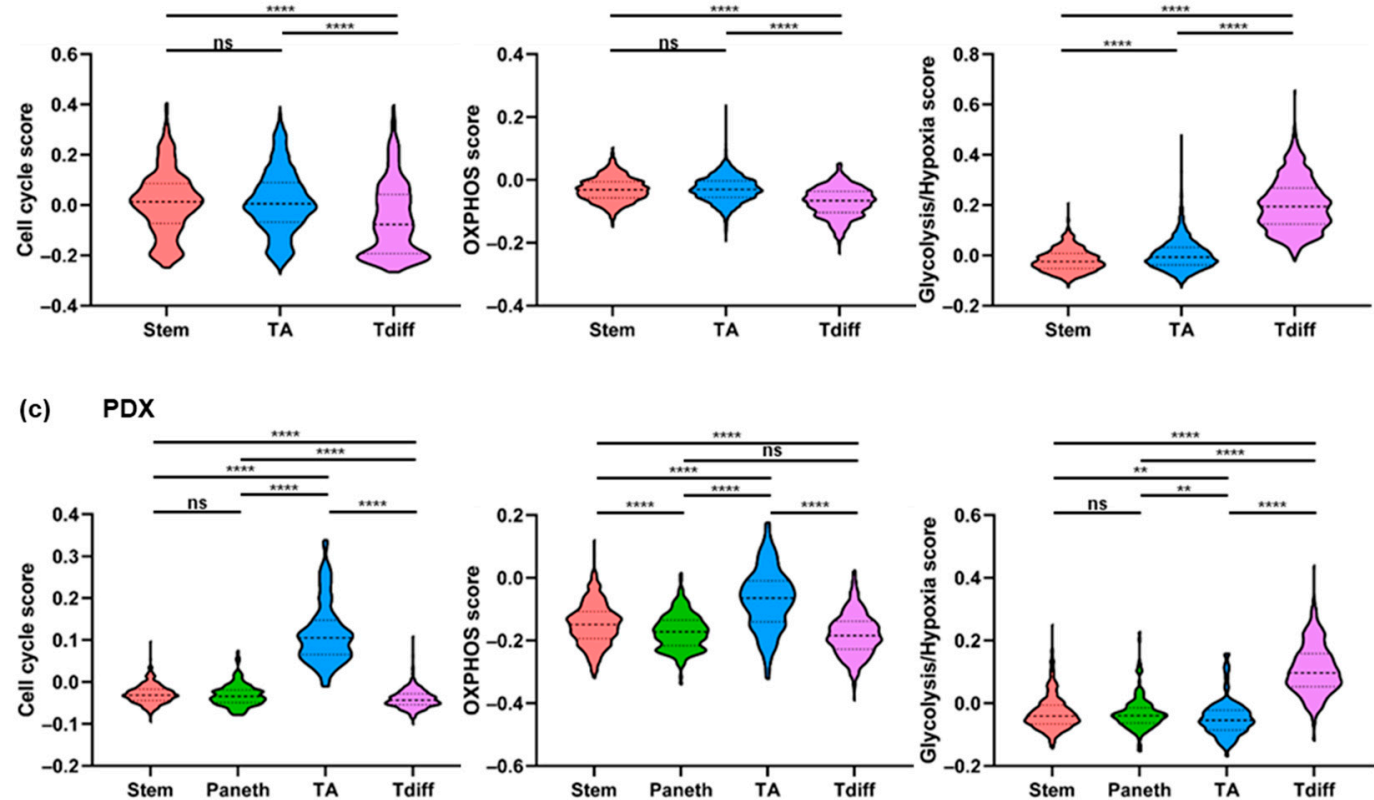

(d) Primary
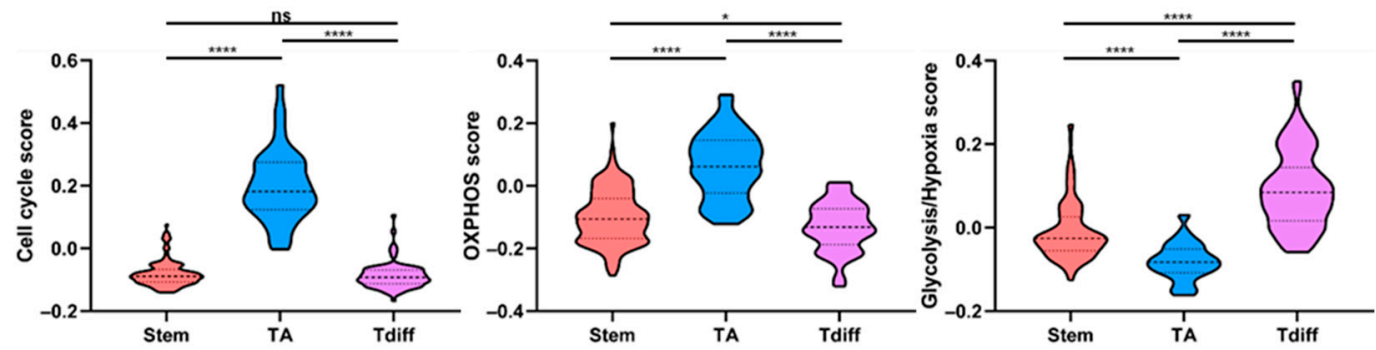

Figure 3. Cell state scores for cell type-specific cell subsets inferred by non-negative matrix factorization. (a-d) Cell cycle, oxidative phosphorylation (OXPHOS), and glycolysis/hypoxia scores (signatures G2/M, OXPHOS_2, and Hypoxia/Glycolysis_2, respectively) for cells of (a) spheroids ( $n=8$ LGR $5^{+}$cultures), (b) patient-derived organoid (PDO; O1), (c) patient-derived xenograft (PDX; X1), and (d) merged tumor epithelial cells (T1-T3) classified under active cell type-specific meta-signatures: stem-like (spheroids: $n=467$; PDO: $n=944$; PDX: $n=667$; primary: $n=124$ ), Paneth-like (spheroids: $n=357$; PDX: $n=189$ ), transit-amplifying (TA)-like (spheroids: $n=554$; PDO: $n=3,967$; PDX: $n=100$; primary: $n=49$ ), terminally differentiated (Tdiff)-like cells (spheroids: $n=486$; PDO: $n=639$; PDX: $n=424 ;$ primary: $n=80$ ). $p$-Values were calculated based on the Mann-Whitney Test (two-tailed). ${ }^{*} p<0.05 ;{ }^{* *} p<0.01 ;{ }^{* * * *} p<0.0001$; ns, not significant. Dashed lines indicate medians. Upper and lower dotted lines indicate $75 \%$ and $25 \%$ percentiles, respectively. 


\subsection{Cell States in Patient-Derived CRC Organoids, Xenografts, and Primary Tumors}

To assess whether cell types and transcriptional programs identified in tumor spheroids are present in other $L G R 5^{+} \mathrm{CRC}$ models and patient tumors, we analyzed three patientderived organoids (PDOs; O1-O3), two patient-derived xenografts (PDXs; X1, X2), and cells from three primary tumor samples (T1-T3) by droplet-based scRNA-seq [37,38] (Table 1). 3003-8785 cells passed quality control per PDO. A mean of 4176-5542 genes per cell were detected. For the PDXs, 1475 (X1) and 1070 cells (X2) passed quality control, with a mean of 1841 and 4598 detected human genes per cell, respectively (Table 2).

To distinguish functionally distinct subpopulations, LGR5 levels were determined and sufficient levels detected in O1, O3, and X1. Since the absolute cell numbers after quality control in the primary tumors were low (T1: 362; T2: 538; T3: 724 cells), the three primary samples were merged and analysis focused on epithelial cells only (total: 253 cells). As observed in spheroids, clustering of cells from LGR5 $5^{+}$PDO, PDX, and primary tumor cells revealed subpopulations of stem-like, TA-like, or Tdiff-like cells. Additionally, a prominent fraction of Paneth-like (deep crypt secretory-like, REG4 ${ }^{+}$) cells [39] was detected in the PDX (Figure S3a-c).

Importantly, applying the signatures identified by NNMF of spheroid scRNA-seq data (Table S1) revealed similar trends for heterogeneous metabolic states associated with distinct cell types, that is, OXPHOS in stem-like and TA-like, and glycolysis/hypoxia in Tdiff-like cells (Figure $3 \mathrm{~b}-\mathrm{d}$ ). This shows that transcriptional states and cellular composition identified in spheroids are representative of further patient-derived CRC models as well as patient tumors.

\subsection{Spatial Distribution of OXPHOS and Distinct Cell Types in CRC Spheroids}

To analyze spatial organization of metabolic states, we stained spheroids with mitochondrial live-dyes for visualization of mitochondrial membrane potential (MMP) and OXPHOS activity. Histological examination of spheroids ( $n=3$ cultures) revealed crypt-like structures formed by partially polarized cells around lumina, morphologically showing some degree of differentiation. Cells within individual spheroids demonstrated highly heterogeneous MMP, with MMPhigh cells consistently localized at outer 'budding' regions of spheroids and around crypt-like structures (Figure S4a).

Multiplexed RNA fluorescence in situ hybridization (FISH) for intestinal cell type markers LGR5 (stem-like), DEFA5 (Paneth-like), and FABP1 (Tdiff-like) resulted in discrete staining of individual cells by either a single or none of the markers, indicating existence of distinct intestinal cell types in all three patient cultures. Cellular subtypes also showed tendencies for spatial localization. $D E F A 5^{+}$cells were primarily detectable in inner regions of spheroids. $L G R 5^{+}$cells preferably localized towards outer regions. Frequently, $D E F A 5^{+}$ cells were identified in proximity to $L G R 5^{+}$cells (Figure $4 \mathrm{a}, \mathrm{b}$ ). In the intestinal crypt, $L G R 5^{+}$cells reside at the crypt base [27,40], and-in line with our observations-imaging of intestinal organoids has shown localization of $L G R 5^{+}$cells close to Paneth cells [41]. 
(a)
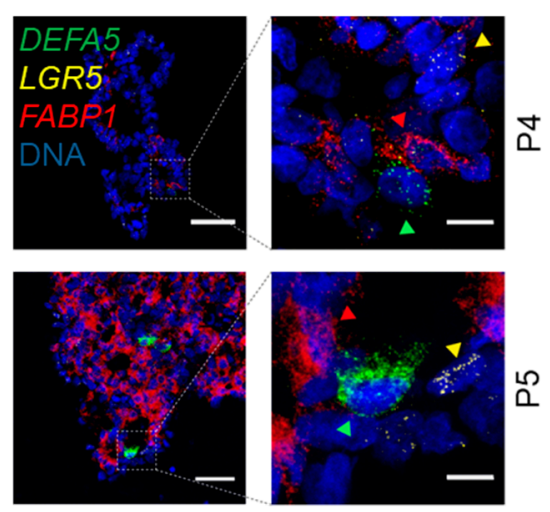

(c)

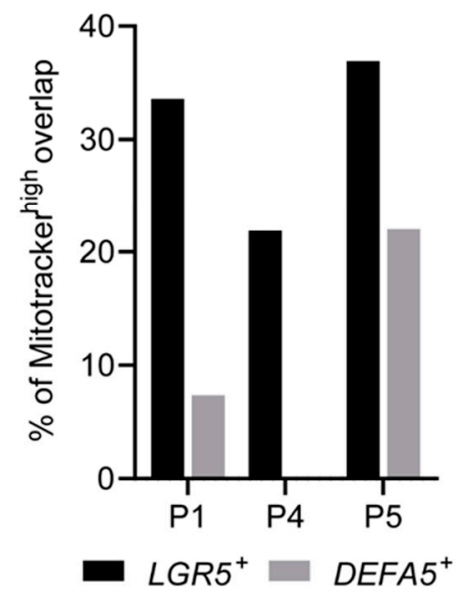

(b)
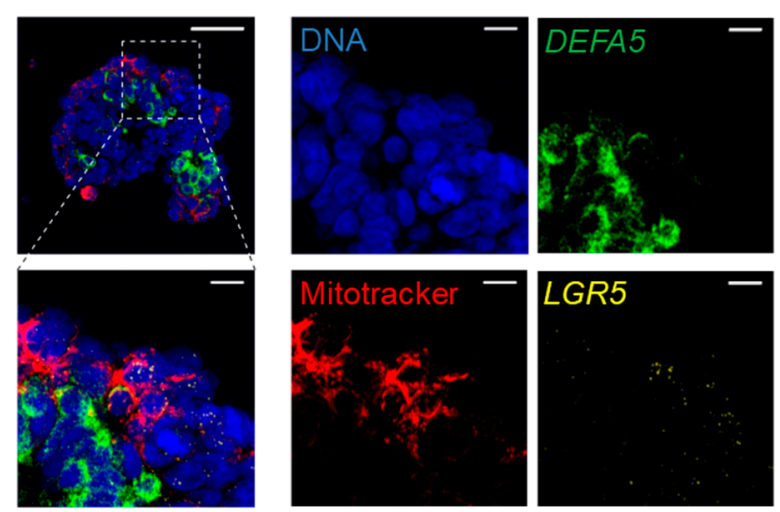

(d)

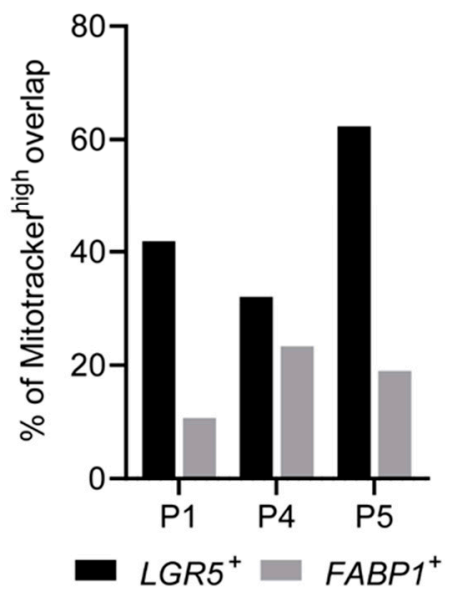

Figure 4. Spatial distribution of metabolic activity and distinct cell types in individual colorectal cancer (CRC) spheroids. (a) Histological sections of CRC spheroids co-stained for representative lineage-specific marker genes by RNA fluorescence in situ hybridization (FISH). Left: Overview images. Scale bar, $50 \mu \mathrm{m}$. Right: Magnified images representing dashed box regions in overview images ( $4 \times$ digital zoom). Scale bar, $10 \mu \mathrm{m}$. DEFA5: Paneth-like, FABP1: terminally differentiated-like, LGR5: stem-like cells. Colored arrowheads mark associated subtypes in magnified images. Images represent z projections from $10 \mu \mathrm{m}$ slices and DNA is counterstained by $6^{\prime}$-diamidino-2-phenylindole (DAPI). (b) Histological section of a spheroid (P1) stained for cell type-specific marker genes (RNA-FISH) and mitochondria (Mitotracker). Top left: Merged overview image. Scale bar, $50 \mu \mathrm{m}$. Bottom left: Magnification of dashed region in top left image (4× digital zoom). Scale bar, $10 \mu \mathrm{m}$. Center and right: Single channels. Scale bar, $10 \mu \mathrm{m}$. Images represent z projections from $10 \mu \mathrm{m}$ slices and DNA is counterstained by DAPI. (c,d) Fraction of Mitotracker 'ON' cells as determined by automated image analysis pipeline. (c) $L G R 5^{+}$or DEFA5 ${ }^{+}$cells (total number of cells analyzed: P1: $n=7379 ;$ P4: $n=2670 ;$ P5: $n=2213$ ). (d) LGR5 or FABP1 ${ }^{+}$cells (total number of cells analyzed: P1: $n=3403$; P4: $n=1580$; P5: $n=1601$ ).

To correlate MMP with specific cell types, we combined mitochondrial staining and multiplexed RNA-FISH, showing $D E F A 5^{+}$and $F A B P 1^{+}$cells to be largely excluded from $\mathrm{MMP}^{\text {high }}$ regions, whereas $L G R 5^{+}$cells were primarily located in MMPhigh regions. Matching our scRNA-seq results, quantitative image analysis in thousands of single cells revealed that the fraction of $L G R 5^{+}$cells located in MMPhigh regions is indeed much higher compared to $D E F A 5^{+}$and $F A B P 1^{+}$cells in all examined cultures $(n=3$; Figure $4 \mathrm{c}, \mathrm{d}$, Figure $\mathrm{S} 4 \mathrm{~b}, \mathrm{c})$.

Hence, in situ RNA fluorescence microscopy further confirmed cell type-specific metabolic preferences of putative stem-like, Paneth-like, and Tdiff-like cell subtypes in CRC. In addition, metabolic activities of cellular subtypes are associated with specific spatial localization within spheroids.

\subsection{Heterogeneous Energy Metabolism in Patient Tumors}

Identification of cell type-specific metabolic preferences in patient-derived CRC cultures raised the question whether heterogeneously expressed metabolic signatures can be 
identified directly in CRC patient tumors. To address this, we analyzed primary tumors ( $n=25$ patients) and liver metastases ( $n=25$ patients) by immunohistochemistry for expression of LDH-A and CA9 (Figure S5a,b) as marker genes of hypoxia/glycolysis and Tdiff signatures (Figure S1f, Table S1).

Within the majority of examined specimens, immunohistochemical analysis revealed that only subfractions of all cells express LDH-A and CA9, indicating existence of metabolic heterogeneity within individual patient tumors. Despite high expression of the proliferation marker MKI67, previously reported to preferentially mark TA-like cells [42], regions of CA9 expression were largely overlapping with MKI67- areas in most patient tumors, suggesting that tumor cells with expression of the hypoxia/glycolysis signature were indeed less proliferative, and actively cycling TA-like cells might prefer OXPHOS to generate energy (Figure S5c).

\subsection{Heterogeneous Energy Metabolism in Patient-Derived Models}

To assess whether cellular subfractions with distinct OXPHOS activities can be identified in viable cells, we used an MMP dye for flow cytometry allowing distinction of cells with different mitochondrial activity based on fluorescence intensity. Indeed, heterogeneous fluorescence intensities allowed separation of populations with different MMP (MMPlow, MMPhigh; Figure 5a).

To understand whether heterogeneous metabolic activity is relevant in patient CRC tumors, we determined OXPHOS activity of two freshly purified patient tumors and a patient tumor expanded as PDX in vivo by flow cytometry-based MMP analysis. In all samples, two cell populations with distinct MMP were identified (Figure 5a), indicating that heterogeneous mitochondrial activity also exists in PDXs and patient tumors.

This finding was further supported by proteomic analysis of MMPlow and MMPhigh populations of $L G R 5^{+}$(i.e., $L G R 5$ score > 1) spheroid cultures (P1, P4, P7, P11) which revealed differentially abundant proteins between the two populations. Interestingly, three proteins contributing to the stem-like signature (PROX1, GRN, DEFA6; Table S1) were significantly higher abundant in MMPhigh compared to MMPlow (Figure S5d).

\subsection{Increased Spheroid and Tumor Formation Capacity in OXPHOS ${ }^{\text {High }}$ Cells}

scRNA-seq data suggested that subfractions of MMPlow and MMPhigh spheroid cells preferentially harbor Tdiff-like and Paneth-like $\left(\mathrm{MMP}^{\mathrm{low}}\right)$ or stem-like and TA-like tumor cells (MMPhigh). As spheroid and tumor forming capacity is supposed to be restricted to stem-like tumor cells [43], we calculated spheroid-forming cell (SFC) frequencies in vitro and TIC frequencies in vivo by limiting dilutions of sorted MMPlow and MMPhigh cell fractions.

SFC frequencies were strongly increased in MMPhigh cell fractions compared to $M_{M}{ }^{\text {low }}$ fractions or bulk spheroid cells in four out of five cultures (Figure 5b). Spheroid cells (P1) sorted according to JC-1 aggregation-a different MMP indicator-also demonstrated increased SFC frequency in the MMP ${ }^{\text {high }}$ subpopulation (MMPhigh: 1/26; MMPlow: 1/46; Figure S5e).

As increased mitochondrial OXPHOS is linked to enhanced ROS levels [23], we further assessed the association of SFC frequency and OXPHOS by staining spheroid cells (P4) with a live-dye fluorescent upon ROS oxidation. In vitro limiting dilutions revealed substantial enrichment of SFCs in the sorted ROS ${ }^{\text {high }}$ compared to the ROS $^{\text {low }}$ subpopulation (ROS ${ }^{\text {high }}$ : 1/9; ROS low: 1/117; Figure S5f). 

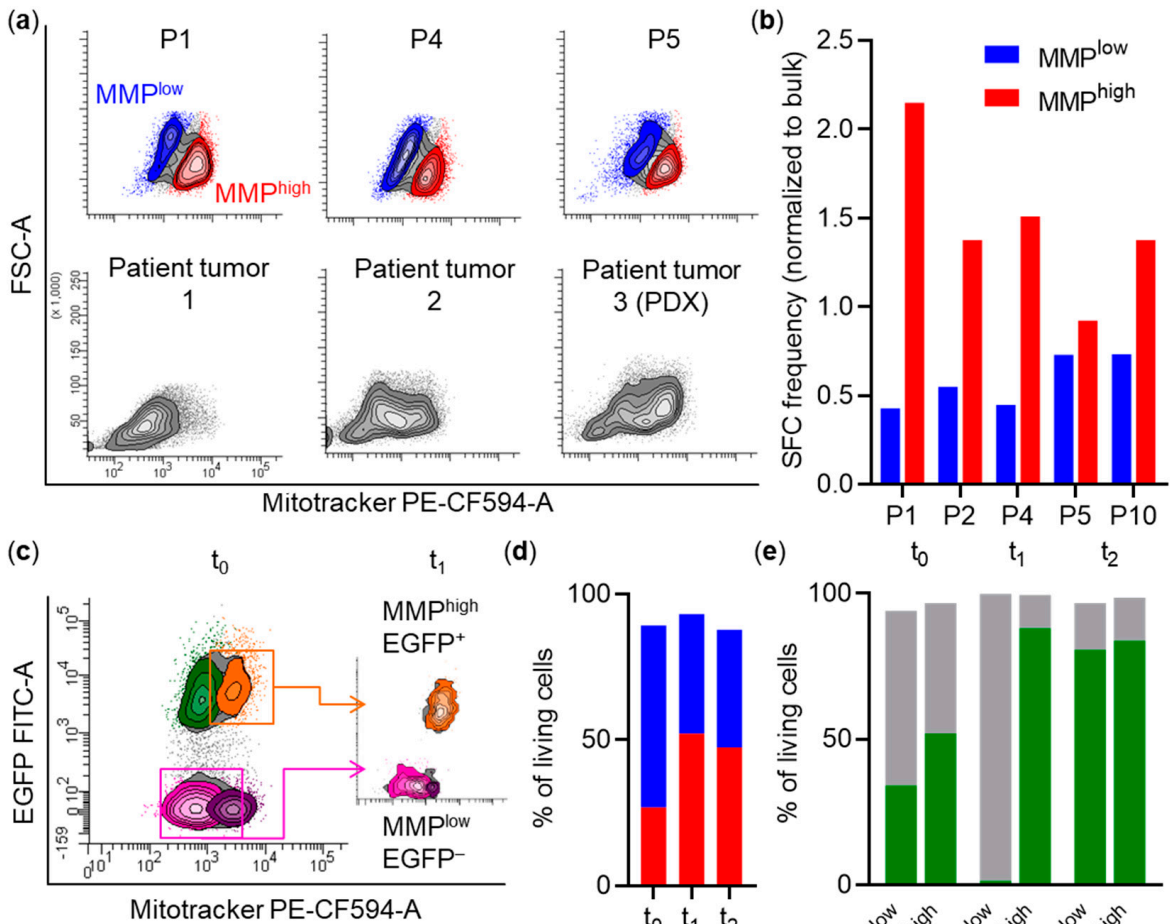

(d)

(e)
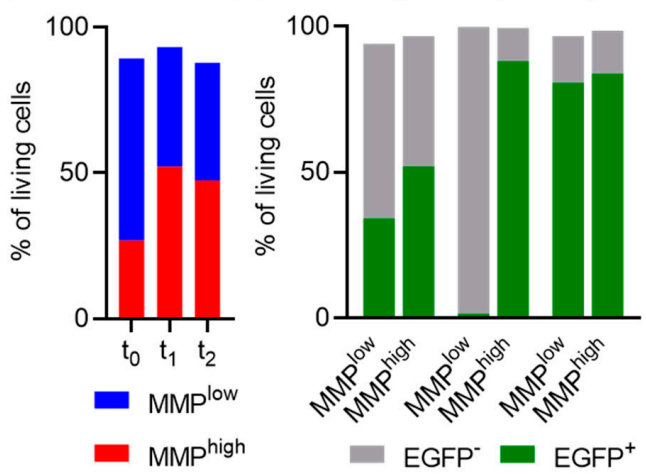

(f)

\begin{tabular}{|c|c|c|c|c|c|c|c|}
\hline \multicolumn{8}{|c|}{ P1 } \\
\hline & $D$ & $\begin{array}{l}1 \times \\
10^{6}\end{array}$ & $\begin{array}{l}1 \times \\
10^{5}\end{array}$ & $\begin{array}{l}1 \times \\
10^{4}\end{array}$ & $\begin{array}{l}1 \times \\
10^{3}\end{array}$ & & TIC freq \\
\hline \multirow{2}{*}{ MMPlow } & $\mathrm{R}$ & 4 & 2 & 0 & 0 & & \multirow{2}{*}{$\begin{array}{c}1 \text { in } \\
211,305\end{array}$} \\
\hline & $\bar{T}$ & 4 & 5 & 6 & 6 & & \\
\hline \multirow{2}{*}{ MMPhigh } & $\mathrm{R}$ & 4 & 5 & 0 & 0 & & \multirow{2}{*}{$\begin{array}{c}1 \text { in } \\
46,535\end{array}$} \\
\hline & $\bar{T}$ & 4 & 5 & 6 & 6 & & \\
\hline \multicolumn{8}{|c|}{$\mathrm{P} 4$} \\
\hline & D & $\begin{array}{l}3 \times \\
10^{5}\end{array}$ & $\begin{array}{l}3 \times \\
10^{4}\end{array}$ & $\begin{array}{l}3 \times \\
10^{3}\end{array}$ & $\begin{array}{l}3 \times \\
10^{2}\end{array}$ & $\begin{array}{l}3 \times \\
10^{1}\end{array}$ & TIC freq \\
\hline \multirow{2}{*}{ MMPlow } & $\mathrm{R}$ & 3 & 4 & 5 & 0 & 0 & \multirow{2}{*}{$\begin{array}{c}1 \text { in } \\
2,089\end{array}$} \\
\hline & $T$ & 3 & 4 & 6 & 5 & 6 & \\
\hline \multirow{2}{*}{ MMPhigh } & $R$ & 3 & 4 & 5 & 4 & 1 & \multirow{2}{*}{$\begin{array}{l}1 \text { in } \\
249\end{array}$} \\
\hline & $\mathrm{T}$ & 3 & 4 & 5 & 6 & 6 & \\
\hline
\end{tabular}

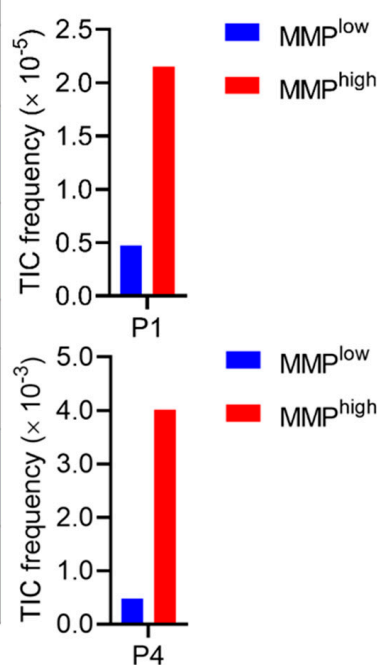

Figure 5. Association of tumor-initiating cell (TIC) activity and mitochondrial membrane potential (MMP). (a) Top: Heterogeneous MMP staining (Mitotracker) of spheroid cells assessed by flow cytometry (representative plots shown). Colored cell populations indicate sorted fractions. Bottom: Heterogeneous MMP staining pattern in tumor cells. Axis scale numbers are representative for all plots. PDX, patient-derived xenograft. (b) Spheroid-forming cell (SFC) frequencies of MMP sorted spheroid cells (P1, P4: $n=3$; P5: $n=2$; P2, P10: $n=1$ ) determined by in vitro limiting dilutions. SFC frequencies were calculated based on sphere formation 5-7 days after seeding and normalized to bulk (P1, P4, P5: $n=2 ;$ P2, P10: $n=1)$. (c) Experimental layout of co-cultivation experiments. $\mathbf{x}$ - and $\mathbf{y}$-axis are displayed biexponentially. Results for a representative spheroid culture (P1) are shown. Axis scale numbers are representative for all plots. EGFP, enhanced green fluorescent protein. (d,e) Composition of (d) MMPlow and MMPhigh cells or (e) EGFP' and EGFP cells in the MMPlow and MMPhigh subpopulations over time. $t_{0}$ : before, $t_{1}$ : directly after, $t_{2}: 21$ days after sort. (f) Results of limiting dilutions in vivo. Left: Overview of dose (D) and response (R). Right: TIC frequencies of MMP sorted spheroid cells. TIC frequencies were calculated based on tumor formation seven weeks (P1: $n=42$ mice) or five weeks (P4: $n=48$ mice) after transplantation. Freq, frequency; $\mathrm{T}$, tested. 
We then asked whether MMPhigh cells exhibit a growth advantage in competition with MMPlow cells. Spheroid cultures (P1, P4, P5) were transduced with a lentiviral vector encoding for enhanced green fluorescent protein (EGFP) under the control of the human phosphoglycerate kinase (PGK) promoter in order to allow follow up of sorted populations by assigning presence or absence of EGFP expression to the metabolic state at the time of sort. To achieve this, $\sim 40-50 \%$ EGFP $^{+}$cultures were stained for MMP $\left(\mathrm{t}_{0}\right)$ and cells were sorted as co-cultures of $\mathrm{MMP}^{\text {high }} \mathrm{EGFP}^{+}$and $\mathrm{MMP}^{\text {low }} \mathrm{EGFP}^{-}$spheroid cells (1:1 ratio; $\left.t_{1}\right)$. After three weeks $\left(t_{2}\right)$, despite similar relative contributions of MMPlow and MMPhigh fractions, co-cultures were nearly completely $\mathrm{EGFP}^{+}$, indicating a growth advantage of MMPhigh compared to MMPlow cells (Figure $5 \mathrm{c}-\mathrm{e}$ ).

To quantify TIC frequency in MMPhigh and MMPlow subpopulations in vivo, spheroid cultures $(n=2)$ were sorted according to MMP. Descending cell numbers of each population were subcutaneously injected into NSG mice. For P1, 42 mice with four different dilutions $\left(10^{3}-10^{6}\right.$ cells $)$, for $\mathrm{P} 4,48$ mice with five different dilutions $\left(3 \times 10^{1}-3 \times 10^{5}\right.$ cells) were transplanted. For all mice where endpoint criteria have not been reached before, tumor formation was assessed simultaneously at defined endpoints (P1: seven weeks; P4: five weeks after transplantation). Importantly, in both tested cultures, calculated TIC frequencies were substantially increased in $\mathrm{MMP}^{\text {high }}$ compared to MMP ${ }^{\text {low }}$ cells (P1: 1/46,535 vs. 1/211,305; P4: $1 / 249$ vs. $1 / 2089$ for MMPhigh vs. MMPlow , respectively; Figure 5f), demonstrating strong enrichment of stem-like tumor cells in the MMPhigh population.

Cell type-specific metabolic preferences might represent a targetable metabolic vulnerability in CRC. To test this hypothesis, we assessed the impact of carbonyl cyanide $m$-chlorophenyl hydrazine (CCCP), a drug perturbing adenosine triphosphate synthesis by transporting protons across the mitochondrial inner membrane [44], on SFC frequency ( $n=3$ spheroid cultures). Upon $4 \mathrm{~h}$ pretreatment with $25 \mu \mathrm{M}$ CCCP, a lower SFC frequency of CCCP compared to dimethyl sulfoxide (DMSO) treated cells was observed for all cultures tested (P1: $1 / 19$ vs. $1 / 14$; P4: $1 / 18$ vs. $1 / 9$; P5: $1 / 68$ vs. $1 / 14$ for CCCP vs. DMSO treated, respectively; Figure S5g), indicating sensitivity of stem-like cells towards OXPHOS inhibition.

\section{Discussion}

We here analyzed functional CRC intra-tumor heterogeneity at single-cell level and demonstrate that distinct functional programs within individual CRC cells can be assigned to specific cellular subpopulations.

In healthy tissues including normal intestine, functional cellular heterogeneity is established by differentiation processes of stem and progenitor cell populations, which control the tissues' functionality in a demand-dependent manner [27]. Similarly, in CRC and other solid tumors as well as in hematological malignancies, functional heterogeneity of tumor and non-tumor cells in the surrounding microenvironment exists and acts as driver of tumor progression [31,45]. Although the majority of tumor cells in CRC cycles actively, we identified proliferatively inactive cells in patient-derived cultures and within established xenograft tumors in vivo-in line with recent data on the healthy intestine [46]. Nevertheless, these cells eventually can re-enter the cell cycle and exhibit TIC activity, suggesting that cells escape from a quiescent state, possibly driven by cellular plasticity as described before for CRC [47]. Accordingly, slow or non-cycling cells were suggested to exhibit increased chemoresistance and drive relapse following initial successful therapy [17,48].

This has striking parallels to the normal intestine, where ablation of stem cells under pathological conditions (e.g., irradiation) can be compensated by a reserve pool of stem cells that are rare during homeostasis but can regenerate all different cell populations including stem, progenitor, and differentiated cell types upon activation, thereby maintaining a functional intestine after tissue injury [49].

The complex composition of different subpopulations within normal and malignant intestinal epithelium and their dynamic interactions are poorly understood. Their characterization has been hampered by the dependency of experimental approaches on purifying cell 
populations, which cannot fully distinguish between or comprehensively capture distinct cell types and intermediates and might fail to detect rare and poorly characterized cell populations. Recent studies shed light on this complexity by utilizing single-cell approaches to detect and characterize rare cell types in the normal intestine and CRC [42,46,49-53]. We here demonstrate that scRNA-seq further allows the identification of cell type-specific expression modules in CRC and enables identification of functional states during TIC differentiation based on transcriptional heterogeneity.

In line with observations in other entities, transcriptional programs across multiple CRC patients were dominated by inter-patient heterogeneity, most likely due to individual genetic and epigenetic alterations $[21,25,54]$. Interestingly, most patient-derived spheroid cells clustered according to primary tumor or metastasis site, suggesting either a stable effect of tumor environment on transcriptional programs or selection of tumor cells with specific expression profiles.

Gene sets most heterogeneously expressed within individual spheroids and PDOs included genes specifically expressed in distinct cell types of the normal intestinal epithelium (e.g., a gene set including LGR5 for stem-like, a gene set including KRT20 for Tdiff-like cells) [55]. This further supports the notion that, in CRC, there exist functionally distinct cell types that phenotypically reflect those of the normal intestinal epithelium $[6,8]$. Still, in contrast to the normal intestinal epithelium where distinct cellular subpopulations can be discriminated in high resolution by scRNA-seq technologies [55], gene expression within identified subfractions of CRC was less distinct. However, individual subfractions shared transcriptional traits, potentially reflecting continuous cell type transitions after malignant transformation comparable to reports on hematopoietic stem cell differentiation [56]. In glioblastoma, bulk RNA-sequencing of individual tumors was used to analyze transcriptional heterogeneity and identified different tumor subtypes, while scRNA-seq revealed different proportions of cell types within individual tumors underlying transcriptional heterogeneity rather than distinct homogeneous tumor subtypes [54]. This is in line with our data showing cellular diversity of cell types and cell states within individual patient tumors. Of note, four out of 12 spheroid cultures did not meet inclusion criteria for NNMF analysis due to low LGR5 scores. Accordingly, previous findings show that, while $L G R 5^{+}$ tumor cells can be detected in tumors from all CRC subtypes independent of their cellular composition [53], up to a third of individual CRCs tumors may lack detectable LGR5 levels [14]. Furthermore, LGR5 plasticity has recently been shown to drive CRC metastasis [57]. In the presented study, we only focused on patient-derived cultures with high expression of $L G R 5$. Future analyses of the hierarchical organization of $L G R 5^{-}$cultures and existing cellular subpopulations in comparison to the cellular subpopulations and cellular states described in this study could further widen the understanding of cellular heterogeneity in CRC.

Our approach to decipher transcriptional programs heterogeneously expressed in functionally distinct CRC cell subfractions identified heterogeneous gene expression programs related to cell cycle, immune response, and metabolic states like OXPHOS and glycolysis. Given the considerable functional and proliferative differences between distinct cell populations, cell-to-cell variability in energy turnover and demand appears likely. A recent study has linked decreased biosynthetic capacities to differentiation [58]. As OXPHOS can be more efficient in energy production [59], highly proliferative TA-like tumor cells might prefer OXPHOS over glycolysis to generate energy. Even though such cell type-specific metabolic identities are known from the normal intestinal epithelium [23], distinct metabolic preferences within normal and malignant stem cell systems are not uniform across different tissue types and tumor entities, and are not necessarily correlated with proliferation activity in general. For example, TICs in hepatocellular carcinoma [60], breast cancer [61], osteosarcoma [62], and nasopharyngeal carcinoma [63] rely on glycolysis for tumor formation, while TICs in pancreatic ductal adenocarcinoma [64], glioma [65], and acute myeloid leukemia [66] prefer OXPHOS. Importantly, tumor cells can also alternate between glycolysis and OXPHOS, thereby adapting to metabolic challenges [67]. 
Here, we were able to assign the metabolic demand of OXPHOS to functionally relevant stem-like and TA-like cells and observed substantial enrichment of self-renewing and proliferating SFCs and TICs in OXPHOS ${ }^{\text {high }}$ cell subfractions. As a consequence, inhibition of OXPHOS impaired spheroid formation in vitro identifying OXPHOS as a novel druggable target in CRC. Since high OXPHOS levels were detected in stem-like and TA-like cell compartments, targeting OXPHOS as treatment strategy might eliminate the most self-renewing and proliferating cell types simultaneously.

Interestingly, stem-like tumor cells demonstrated overexpression of OXR1 and PON2, both involved in protection against ROS accumulating as co-product of OXPHOS [34]. Further studies are needed to address whether expression of OXR1 and PON2 may be involved in a mechanism by which this long-lived and thus vulnerable population of stem-like tumor cells protects itself against ROS-mediated damage.

In our proteomic analysis, proteins significantly higher abundant in the MMPhigh subpopulation included PROX1, one of the top markers of the stem signature and usually expressed in the enteroendocrine lineage [51]. Interestingly, PROX1 has been reported to be positively correlated with LGR5 expression in CRC [43] and linked to stem cell maintenance and metastasis $[68,69]$. Another protein significantly more abundant in MMPhigh was DEFA6, a protein expressed in normal Paneth and Paneth-like tumor cells [70]. Its moderate expression in the stem-like cell population might reflect a continuous rather than a stepwise process underlying transition from stem-like to Paneth-like cell subsets (and potentially vice versa) in CRC. While Paneth cells constitute the niche for LGR5 ${ }^{+}$cells in the small intestinal epithelium, this function is performed by REG4-expressing deep crypt secretory cells in the colon $[39,71,72]$. REG4 was also included in the NNMF Paneth-like signature, suggesting that both cell types might contribute to this signature.

Of note, the expression signatures identified by scRNA-seq of patient-derived CRC spheroids have shown a prognostic relevance for CRC patients comparable to previously reported subtypes linked to cancer-associated fibroblasts [31] or CMSs [29], indicating that cell types and cell states might indeed be biologically distinct and of potential clinical relevance for CRC patients.

In summary, we here show that distinct functional cell states during TIC differentiation can be identified by single-cell transcriptomes. Targeting differentiation of cancer cells and associated transcriptional states might represent a novel therapeutic strategy for human CRC.

\section{Materials and Methods}

\subsection{Primary CRC Spheroids and Organoids}

Human CRC samples (male and female patients) were obtained from Heidelberg University Hospital in accordance with the Declaration of Helsinki. Informed consent on tissue collection was received from each patient, as approved by the University Ethics Review Board on 19 May 2009 (323/2004) and 7 June 2013 (S-649/2012). Tumor sample processing and purification procedures were described previously $[4,73,74]$.

For generation of three-dimensional spheroid cultures, cells freshly isolated from patient material or PDXs were cultivated in ultra-low attachment flasks (Corning, Corning, NY, USA) in serum-free culture medium (Advanced DMEM/F-12 supplemented with $0.6 \%$ glucose, $2 \mathrm{mM}$ L-glutamine (all ThermoFisher, Waltham, MA, USA), $5 \mathrm{mM}$ HEPES, $4 \mu \mathrm{g} / \mathrm{mL}$ heparin (all Sigma-Aldrich, St. Louis, MO, USA), $4 \mathrm{mg} / \mathrm{mL}$ bovine serum albumin (PAN-Biotech, Aidenbach, Germany)). Growth factors $(20 \mathrm{ng} / \mathrm{mL}$ epidermal growth factor, $10 \mathrm{ng} / \mathrm{mL}$ fibroblast growth factor basic (all R\&D Systems, Minneapolis, MN, USA)) were added twice per week.

To dissociate tumor spheroids, cells were pelleted, resuspended in $0.25 \%$ trypsin-EDTA (ThermoFisher, Waltham, MA, USA), and incubated for $10-30 \mathrm{~min}$ at $37^{\circ} \mathrm{C}$. The reaction was stopped by adding $20 \%$ fetal bovine serum (PAN-Biotech, Aidenbach, Germany) in phosphate-buffered saline (PBS; ThermoFisher, Waltham, MA, USA). Cells were pelleted, resuspended in medium, and filtered through a $40 \mu \mathrm{m}$ cell strainer (Corning, Corning, NY, 
USA). To avoid secondary cell culture artifacts, like hypoxic cores in large spheroids [75], cultures were dissociated at defined, pretested time points 6-14 days before individual experiments.

For generation of three-dimensional organoid cultures, purified cells were seeded in $10 \mu \mathrm{L}$ drops of Cultrex reduced growth factor basement membrane extract (R\&D Systems, Minneapolis, MN, USA) into not-treated 6-well plates (Corning, Corning, NY, USA). Organoids were cultured as previously described with minor modifications $[76,77]$ and in the absence of WNT, R-spondin and Noggin, thereby selecting for tumor cells with activation of $W N T / \beta$-catenin signaling and inhibition of BMP signals $[78,79]$. In brief, cells were cultured in serum-free culture medium (Advanced DMEM/F-12 supplemented with B-27 supplement, $2 \mathrm{mM}$ L-glutamine, $100 \mu \mathrm{g} / \mathrm{mL}$ streptomycin, $100 \mathrm{U} / \mathrm{mL}$ penicillin (all ThermoFisher, Waltham, MA, USA), $10 \mathrm{mM}$ HEPES, $10 \mathrm{mM}$ nicotinamide, $1.25 \mathrm{mM}$ $\mathrm{N}$-acetyl-L-cysteine, $1 \mu \mathrm{M}$ SB 202190, $500 \mathrm{nM}$ A 83-01, $10 \mathrm{nM}$ gastrin, $10 \mathrm{nM}$ prostaglandin $\mathrm{E}_{2}$ (all Sigma-Aldrich, St. Louis, MO, USA), $100 \mu \mathrm{g} / \mathrm{mL}$ primocin (InvivoGen, San Diego, CA, USA)). $20 \mathrm{ng} / \mathrm{mL}$ of epidermal growth factor was added three times per week and medium was exchanged weekly. After seeding, $10 \mu \mathrm{M}$ Y-27632 (StemCell Technologies, Vancouver, BC, Canada) was added. To dissociate tumor organoids, cells were taken up in $0.25 \%$ trypsin-EDTA diluted $1: 1$ in PBS and incubated for $10-20$ min at $37^{\circ} \mathrm{C}$. To enhance dissociation, organoids were mechanically disrupted by pipetting. The reaction was stopped by adding $20 \%$ fetal bovine serum in PBS. Cells were washed twice with PBS before reseeding.

Spheroid and organoid cultures were authenticated using Multiplex Cell Authentication by Multiplexion (Heidelberg, Germany) as described [80]. The SNP profiles matched known profiles or were unique. The purity of spheroid and organoid cultures was validated using the multiplex cell contamination test by Multiplexion (Heidelberg, Germany) as described recently [81]. No mycoplasma, SMRV or interspecies contamination was detected. To assure pure epithelial cell content and exclude contaminations with murine or hematopoietic cells, established cultures were tested for EPCAM, H2kd, and CD45 expression by flow cytometry.

\subsection{Laboratory Animals}

Male and female immunodeficient NSG mice purchased from The Jackson Laboratory (Bar Harbor, ME, USA) were further expanded in the Centralized Laboratory Animal Facilities of the DKFZ, Heidelberg. Animals were group-housed in standard individually ventilated cages with wood chip embedding (LTE E-001, ABEDD, Vienna, Austria), nesting material, autoclaved tap water and ad libitum diet (autoclaved mouse/rat housing diet 3437, Provimi Kliba, Kaiseraugst, Switzerland). Room temperature and relative humidity were adjusted to $22.0 \pm 2.0^{\circ} \mathrm{C}$ and $55.0 \pm 10.0 \%$, respectively, in accordance with Appendix A of the European Convention for the Protection of Vertebrate Animals used for Experimental and Other Scientific Purposes from 19 March 1986. According to FELASA recommendations, all animals were housed under strict specific pathogen-free conditions. The light/dark cycle was adjusted to $14 \mathrm{~h}$ lights on and $10 \mathrm{~h}$ lights off with the beginning of the light and dark period set at 6 am and $8 \mathrm{pm}$, respectively. The age of transplanted mice was at least seven weeks. All animal experimentation performed in this study was conducted according to national guidelines and was reviewed and confirmed by an institutional review board/ethics committee headed by the responsible animal welfare officer. The Regional Authority of Karlsruhe, Germany finally approved the animal experiments as the responsible national authority (approval numbers G228/12 (29 January 2013), G49/14 (26 June 2014), G233/15 (17 November 2015)).

\section{3. scRNA-seq of Spheroids}

To generate single-cell suspensions, cells were trypsinized as described. Trypsinization was enhanced by applying shear forces with a pipette every $5 \mathrm{~min}$. After stopping the reaction, cells were washed twice with PBS and filtered through a 15-20 $\mu \mathrm{m}$ cell strainer 
(PluriSelect, Leipzig, Germany). To count and test for cell viability using an automated cell counter (Countess, ThermoFisher, Waltham, MA, USA), single-cell suspensions were stained with Hoechst and propidium iodide (ReadyProbes Cell Viability Imaging Kit, ThermoFisher, Waltham, MA, USA) for $10 \mathrm{~min}$ at room temperature. Only samples with at least $85 \%$ viability were used for further processing. For isolation of single cells, reverse transcription, and cDNA amplification, the Rapid Development Kit (Wafergen, Fremont, CA, USA; compare: SMARTer iCELL8 3' DE Reagent Kit, TakaraBio, Kusatsu, Japan) for inchip reverse transcription-PCR amplification with the iCELL8 system (TakaraBio, Kusatsu, Japan) [19] was used. The cell suspension was diluted to 25 cells $/ \mu \mathrm{L}$. Cells were dispensed from a 384-well source plate into a nanowell chip (SmartChip v1/v2 kit, TakaraBio, Kusatsu, Japan; P7: v2; others: v1) containing uniquely barcoded oligo-dT primers for each well, resulting in up to $30 \%$ of wells containing single cells following Poisson distribution. Wells were imaged using an automated fluorescence microscope (BX43, Olympus, Shinjuku, Japan) and image processing was performed using CellSelect (TakaraBio, Kusatsu, Japan). Additional manual curation for multiplets and dead cells was performed. $50 \mathrm{~nL}$ RT/Amp solution was dispensed into nanowells (master mix: $56 \mu \mathrm{L} 5 \mathrm{M}$ betaine (Sigma-Aldrich, St. Louis, MO, USA), $24 \mu \mathrm{L} 25 \mathrm{mM}$ dNTP mix (TakaraBio, Kusatsu, Japan), $3.2 \mu \mathrm{L} 1 \mathrm{M}$ magnesium chloride (ThermoFisher, Waltham, MA, USA), $8.8 \mu \mathrm{L} 100 \mathrm{mM}$ dithiothreitol, $61.9 \mu \mathrm{L} 5 \times$ SMARTScribe first-strand buffer, $33.3 \mu \mathrm{L} 2 \times$ SeqAmp PCR buffer, $4.0 \mu \mathrm{L} 100 \mu \mathrm{M}$ RT E5 oligo, $8.8 \mu \mathrm{L} 10 \mu \mathrm{M}$ Amp primer (all TakaraBio, Kusatsu, Japan), $1.6 \mu \mathrm{L} 100 \%$ Triton X100 (ThermoFisher, Waltham, MA, USA), $28.8 \mu \mathrm{L}$ SMARTScribe reverse transcriptase, $9.6 \mu \mathrm{L}$ SeqAmp DNA polymerase (all TakaraBio, Kusatsu, Japan)). In-chip RT/Amp amplification was performed for 18 amplification cycles (Bio-Rad, Hercules, CA, USA; modified for iCELL8 chips). Libraries were pooled, concentrated (DNA Clean\&Concentrator-5, Zymo Research, Irvine, CA, USA), purified (0.6× Ampure XP beads, Beckman Coulter, Brea, CA, USA), and assessed for DNA quality (Bioanalyzer and High Sensitivity DNA Kit, Agilent, Santa Clara, CA, USA). Next generation sequencing libraries were constructed following manufacturer's instructions using the Nextera XT DNA Library Prep Kit (Illumina, San Diego, CA, USA) and sequenced using NextSeq500 (Illumina, San Diego, CA, USA; highoutput mode, paired-end; v1 chip: $21 \times 70$ bp; v2 chip: $24 \times 67 \mathrm{bp}$ ).

\section{4. scRNA-seq of Tumors, PDXs, PDOs}

To generate single-cell suspensions, cells were trypsinized as described. After stopping the reaction, cells were washed with PBS and filtered through a $40 \mu \mathrm{m}$ cell strainer. Cells were washed, resuspended in PBS supplemented with $0.05 \%$ bovine serum albumin, and filtered through a $20 \mu \mathrm{m}$ cell strainer. Single-cell suspensions were loaded following the Chromium Single Cell 3' Library Kit v2 $(10 \times$ Genomics, Pleasanton, CA, USA) protocol to generate cell and gel bead emulsions. Reverse transcription, cDNA amplification, and sequencing library generation were performed according to manufacturer's protocol. Each library was sequenced in one lane of the NextSeq500 (Illumina, San Diego, CA, USA; high-output mode, paired-end, $26 \times 49 \mathrm{bp}$ ).

\subsection{Preprocessing and Analysis of iCELL8 Data}

scRNA-seq data were preprocessed using an automated in-house workflow (Roddy; https:/ / github.com/TheRoddyWMS/Roddy). FastQC was used to evaluate read quality. Assignment of iCELL8 library barcodes to corresponding nanowells was performed with the Je demultiplexing suite [82]. Sequences were trimmed for primer sequences, poly-A/T tails, and low-quality ends using Cutadapt with the '-nextseq-trim' option. Mapping to the reference genome hs37d5 was performed (STAR aligner). Quantification of mapped BAM files was performed using featureCounts (reference annotation gencode v19). Only scRNA-seq libraries matching the following criteria were used: (i) $>100,000$ reads, (ii) $>1000$ detected genes, (iii) $<15 \%$ mitochondrial reads. Strong PCA outliers as well as libraries 
with top $5 \%$ of reads for every patient independently were removed. As previously published [25], expression levels based on raw read counts were quantified as

$$
E_{i, j}=\log _{2}\left(\frac{C P M_{i, j}}{10}+1\right),
$$

with $C P M_{i, j}$ as the counts-per-million for gene $i$ in sample $j$. Aggregate expression of each gene across all cells was calculated as

$$
E_{a}=E_{i, j}=\log _{2}\left(\operatorname{mean}\left[E_{i, 1 \ldots n}\right]+1\right)
$$

with genes with $E a<3.5$ being excluded to focus on highly or intermediately expressed genes. Combined filtered and normalized data of all patients were used for evaluation of inter-patient gene expression differences. The $\mathrm{R}$ package Seurat [38] was used for identification of highly variable genes, PCA, clustering, two-dimensional visualization, and differential expression analysis (Wilcoxon rank sum test: adjusted $p$-value $<0.05$; log fold-change $>0.25$ ).

Before combining the data of all patients, relative expression levels were calculated individually for each patient using a mean-centering approach

$$
E r_{i, j}=E_{i, j}-\operatorname{mean}\left[E_{i, 1 \ldots n}\right]
$$

to eliminate global inter-patient gene expression shifts.

PCA was applied and - for visualization - the top 30 genes with low and high scores in the first principal component were clustered using average group linkage (UPGMA) by the 'aheatmap' function from R's 'NMF' package. Gene set enrichment analysis [83] was performed on the top 300 genes with highest and lowest PC scores.

Transcriptional signatures shared across patients were identified using NNMF [24] of mean-centered data of all patients defined as $L G R 5^{+}(n=8$ patients; Table 2). Analysis was performed in MATLAB (MathWorks, Natick, MA, USA; 'nnmf') with a factor number of $k$ $=25$ and negative events set to 0 . To exclude patient-specific signatures, pairwise overlaps in frequency distributions of cell scores for individual factors were determined and factors with overlaps $<50 \%$ in at least five patients were excluded. Biological relevance of factors and their associated genes was analyzed manually and by gene set enrichment analysis [83]. Factors potentially driven by technical artifacts were excluded. Signature scores were defined as averaged expression of the top 200 genes per factor. To reduce redundancy for visualization, signatures showing similar enrichment and clustering patterns were combined to meta-signatures (Figure S1a-e, Table S1).

Meta-signature scores (calculated based on the combined gene lists of the comprised signatures) were clustered using complete linkage of Euclidean distances. NNMF analysis was repeated with various numbers of factors resulting in identification of similar core signatures.

To test whether cell type-specific transcriptional programs (stem-like, TA-like, Panethlike, Tdiff-like) are active in individual cells or-in other words-to differentiate between cells that belong to the four cell type-specific subpopulations, we adapted the above described cell scoring approach based on the expression of inferred NNMF metasignatures [25] and used control random gene sets as background model to control for technical confounders as library complexity. Cell type-specific transcriptional programs were defined as active if their expression in individual cells was $>1$ standard deviation above the mean across all cells. Inferred cell state-specific signatures were scored for cells of a particular cell type to assess the degree to which cell states are active in specific cell types.

\subsection{Preprocessing and Analysis of $10 x$ Data}

For $10 \times 3^{\prime}$ libraries generated from cells derived from PDOs, PDXs, and primary tumor samples, raw sequencing data were processed using CellRanger $(10 \times$ Genomics, Pleasanton, CA, USA; version 2.1.1). Transcripts were aligned with the $10 \times$ reference 
human genome hg19 1.2.0 and the mouse genome mm10 1.2.0. Quality control and downstream analysis were performed with Seurat (https://github.com/satijalab/seurat; version 3.0.0). Only cells matching the following criteria were used for downstream analysis: PDOs: (i) $>2000$ detected genes, (ii) $<10 \%$ mitochondrial reads; PDXs: (i) $>500$ detected genes, (ii) $<10 \%$ mitochondrial reads for Homo sapiens, and (i) $>1000$ and $<4500$ detected genes, (ii) $<10 \%$ mitochondrial reads for Mus musculus; primary tumor samples: (i) $>200$ and $<6000$ detected genes, (ii) $<15 \%$ mitochondrial reads. Only human cells from the PDXs and epithelial cells $\left(E P C A M^{+}, V I L 1^{+}, C E A C A M 5^{+}, V I M^{-}, S P A R C^{-}\right)$from the primary tumor samples were analyzed.

Subsequent downstream analysis was performed with standard Seurat workflow, including log-normalization and scaling as well as PCA and clustering using the top 2000 variable genes. Datasets were visualized using two-dimensional $t$-distributed stochastic neighbor embedding maps [84]. The three primary tumor samples were aligned using canonical correlation analysis implemented in Seurat [85]. In brief, this method identifies pairwise correspondences between single cells across different datasets belonging to specific biological states, termed 'anchors'. These anchors are the basis of harmonizing datasets. Differentially expressed genes between identified clusters were identified using Wilcoxon rank sum test. Identified clusters were scored for cell state signatures using the 'AddModuleScore' function (Seurat), using gene signatures from NNMF analysis (Table S1).

\subsection{Patient Clustering and Survival Analysis}

Cell type and cell state signatures obtained from spheroid scRNA-seq data (Table S1) were evaluated in a patient survival analysis. Bulk transcriptomic data for COAD patients with available survival data were collected from TCGA (level 3 RNA-seq, $n=328$ patients) [28] and log-transformed. For each TCGA patient, the mean expression of gene signatures was calculated and used to cluster bulk transcriptomes by complete linkage of Euclidean distances. Patients were grouped according to different combinations of cell type and cell state signatures. In a new clustering process, the sample space was progressively subdivided using the main signatures defining each cluster of patients: First, OXPHOS_1, G1/S, G2/M, and stem signatures separate cl2 and cl3 (high) from the rest (low; Euclidean distances). Then, hypoxia/glycolysis_1 and TNF $\alpha \_2$ signatures distinguish cl2 (low) from cl3 (high; Euclidean distances). Next, fatty acid and TNF $\alpha \_1$ signatures separate cl1 (high) from cl4, cl5, and cl6 (Euclidean distances). Subsequently, stem and TA signatures separate cl6 (stem ${ }^{\text {low }}$ ) from cl4 and cl5 (stem ${ }^{\text {high }}$; correlation). Finally, G1/S, G2/M, and OXPHOS_1 signatures also distinguish between cl4 (medium) and cl5 (low; Euclidean distances). Complete linkage of Euclidean distances was used to cluster stem ${ }^{\text {high }}$ and stem ${ }^{\text {low }}$ patients. Kaplan-Meier survival curves were generated using 'survival' and 'survminer' libraries in R. We performed Cox proportional hazards modeling and multivariable models with and without cell type and cell state clusters were compared by performing analysis of variance (ANOVA). 'CMScaller' [29] was used to stratify the TCGA COAD cohort. To generate the contingency table, patients that could not be assigned to a CMS ( $n=19$ patients) were excluded.

\subsection{Genetic Labelling of Spheroids}

For tracking of cells within tumors, lentiviral vector particles encoding for tetracyclineregulated (Tet-off) H2B-GFP were produced in HEK293T cells, concentrated by ultracentrifugation, and titrated on HeLa cells as described [4,5]. Patient-derived spheroid cultures $(n=7)$ were transduced with a multiplicity of infection of 1-20 aiming at transduction efficiencies of $\sim 40 \%$ to avoid multiple vector integrations. Within $24 \mathrm{~h}$ after transduction, $4 \times 10^{5}-1.7 \times 10^{6}$ transduced cells were transplanted under the kidney capsule of NSG mice ( $n=14,1-4$ mice per spheroid culture) anesthetized by $1.75 \%$ isoflurane (Abbott, Chicago, IL, USA) in the breathing air. Mice were checked daily for tumor growth, and starting two weeks prior to tumor harvesting, doxycycline (Genaxxon, Ulm, Germany) was added to the drinking water of tumor-bearing mice to shut down H2B-GFP expression. 
Mice were sacrificed, xenograft tumors were digested as described [5,73], cells were stained with $200 \mathrm{nM}$ TOTO-3 (ThermoFisher, Waltham, MA, USA) in Hank's Balanced Salt solution (Sigma-Aldrich, St. Louis, MO, USA) supplemented with $2 \%$ fetal bovine serum for dead cell exclusion, and tumor cells were sorted according to GFP expression intensity (AriaII and FACS Diva, Becton Dickinson, Franklin Lakes, NJ, USA). GFP signal was detected in the FITC channel (488 nm laser; $505 \mathrm{LP}, 525 / 50$ filter). TOTO-3 signal was detected in the APC channel (633 nm laser; 670/30 filter). Samples were gated for cells (FSC-A vs. SSC-A), singlets (FSC-A vs. FSC-W, SSC-A vs. SSC-W), and living cells (FSC-A vs. APC-A). Populations with high, medium, and low/absent GFP expression were sorted (SSC-A vs. FITC-A), reanalyzed to test for sort efficiency, and serially transplanted into secondary recipient mice $\left(1 \times 10^{2}-4.5 \times 10^{4}\right.$ cells; $n=33$ mice $)$. Mice were monitored daily for tumor formation and sacrificed when tumors reached the maximum tolerable size.

\section{9. $R N A-F I S H$}

For combinatory stainings of mitochondrial activity and mRNA, undissociated spheroids were stained for $3 \mathrm{~h}$ with $100 \mathrm{nM}$ Mitotracker Red CMXRos solution (ThermoFisher, Waltham, MA, USA). For histological preparation, cells were fixed in $4 \%$ formaldehyde (ThermoFisher, Waltham, MA, USA) for $20 \mathrm{~min}$ at $4{ }^{\circ} \mathrm{C}$, washed twice with PBS, and incubated in $30 \%$ sucrose overnight at $4{ }^{\circ} \mathrm{C}$. Samples were embedded (Richard-Allan Scientific Neg-50 Frozen Section Medium, ThermoFisher, Waltham, MA, USA) and frozen in the gaseous phase of liquid nitrogen. Histological sections (10 $\mu \mathrm{m}$ slices) were prepared on a cryostat (Leica, Wetzlar, Germany) and mounted on Superfrost Plus slides (ThermoFisher, Waltham, MA, USA). For RNA-FISH, the RNAscope Multiplex Fluorescent v2 (Bio-Techne, Minneapolis, MN, USA) was used according to manufacturer's instructions with probes targeting mRNAs of LGR5, DEFA5, and FABP1. Alexa488, Atto550, or Atto647 were used as fluorescent dyes. Cryosections were stained with 6'-diamidino-2-phenylindole (DAPI) and mounted in SlowFade Gold Antifade solution (ThermoFisher, Waltham, MA, USA). Images were acquired by confocal laser scanning microscopy (SP8, Leica, Wetzlar, Germany) in 15 z stacks (z range: $20 \mu \mathrm{m}$ ).

For quantitative analysis of RNA-FISH/Mitotracker imaging data, we developed a single-cell image analysis pipeline to relate metabolic activity (Mitotracker) to intestinal subtypes (RNA-FISH). To prepare spheroid images for further analysis, we performed maximum intensity projection on each channel separately. For automated nuclei instance detection and segmentation in spheroids, a deep learning object detection and instance segmentation workflow incorporating Mask R-CNN [86] was implemented. The neural network was initialized using pretrained models trained on the 'Microsoft COCO: Common Objects in Context' dataset [87] and fine-tuned using images of nuclei acquired from various unrelated sources. Maximum intensity projections of DAPI images were used as inputs for the neural network to produce segmentation for each individual nucleus as outputs. Nuclei sizes were calculated using these segmented DAPI masks, and objects smaller than 350 pixels were filtered out and excluded from subsequent analysis.

For quantification and analysis of transcript abundance of marker mRNAs specific for stem-like (LGR5), Paneth-like (DEFA5), and Tdiff-like (FABP1) cells, maximum intensity projections of RNA-FISH channels were binarized using 'Maximum Entropy' thresholding (FIJI/ImageJ; https://imagej.nih.gov/ij/). Transcript abundance was estimated by overlaying nuclei masks on maximum projected probe channels and calculating number of pixels lying within each mask. To account for cytoplasmic fluorescence signals localized outside of nuclei masks, we expanded nuclei before quantification by morphological dilation (two iterations) as implemented in scikit-image (Python). To quantify mitochondrial abundance per cell, Mitotracker signals were quantified similarly, but binarization of fluorescence signal was based on 'Moments' thresholding (FIJI/ImageJ). We then performed k-means clustering on frequency distributions of pixel counts per cell to identify and separate cells into two distinct positive 'ON' (high expression/abundance) and negative 'OFF' (low expression/abundance) states. $k=2$ was used for mRNA probes, while $k=3$ was used for 
Mitotracker signals to better capture gradual differences between cells. Finally, the fraction of stem-like, Paneth-like, and Tdiff-like cells that are Mitotrackerhigh at the same time was calculated by dividing the number of Mitotracker ${ }^{\text {high }} L G R 5^{+}, D E F A 5^{+}$, or $F A B P 1^{+}$cells by the total number of $L G R 5^{+}, D E F A 5^{+}$, or $F A B P 1^{+}$cells.

\subsection{Flow Cytometry and Sorting of Metabolic Subpopulations}

Spheroid cultures were dissociated into single-cell suspensions as described above. Sorted cells were collected in culture medium supplemented with $100 \mu \mathrm{g} / \mathrm{mL}$ streptomycin and $100 \mathrm{U} / \mathrm{mL}$ penicillin.

For MMP staining with Mitotracker, cells were resuspended in $25 \mathrm{nM}$ Mitotracker Red CMXRos in PBS ( $1 \mathrm{~mL}$ per $10^{6}$ cells). Staining was performed for $30 \mathrm{~min}$ at $37^{\circ} \mathrm{C}$. For dead cell exclusion, cells were stained with 200 nM TOTO-3 in PBS. Cells were resuspended in PBS, filtered through a $35 \mu \mathrm{m}$ cell strainer (Becton Dickinson, Franklin Lakes, NJ, USA), and analyzed on a cell sorter (AriaII and FACS Diva). Mitotracker signal was detected in the PE-CF594 channel (561 nm laser; 600 LP, 610/20 filter). TOTO-3 signal was detected in the APC channel (633 nm laser; 670/30 filter). Samples were gated for cells (FSC-A vs. SSC-A), singlets (FSC-A vs. FSC-H, SSC-H vs. SSC-W), and living cells (FSC-A vs. APC-A). Sorting was performed based on Mitotracker signal intensity (FSC-A vs. PE-CF594-A; Figure S6a-f).

For MMP staining with JC-1, cells were counted and resuspended in $1 \mu \mathrm{g} / \mathrm{mL}$ JC-1 (ThermoFisher, Waltham, MA, USA) in PBS ( $1 \mathrm{~mL}$ per $10^{6}$ cells). Staining was performed for $10 \mathrm{~min}$ at $37^{\circ} \mathrm{C}$. For dead cell exclusion, cells were stained with $200 \mathrm{nM}$ TOTO-3 in PBS. Cells were resuspended in PBS, filtered through a $35 \mu \mathrm{m}$ cell strainer, and analyzed on a cell sorter (AriaII and FACS Diva). JC-1 monomer signal was detected in the FITC channel (488 nm laser; 505 LP, 525/50 filter). JC-1 aggregate signal was detected in the PE channel (561 nm laser; 575/25 filter). TOTO-3 signal was detected in the APC channel (633 nm laser; 670/30 filter). Samples were gated for cells (FSC-A vs. SSC-A), singlets (FSC-A vs. FSC-H, SSC-H vs. SSC-W), and living cells (FSC-A vs. APC-A). Sorting was performed based on JC-1 aggregate/monomer ratio (PE-A vs. FITC-A). As negative control, $50 \mu \mathrm{M}$ CCCP (Selleckchem, Houston, TX, USA) was added during the staining.

For ROS staining, cells were resuspended in $5 \mu \mathrm{M}$ CellROX Deep Red Reagent (ThermoFisher, Waltham, MA, USA) in PBS (500 $\mu \mathrm{L}$ per $10^{6}$ cells). Staining was performed for $45 \mathrm{~min}$ at $37^{\circ} \mathrm{C}$. For dead cell exclusion, cells were stained with $1 \mu \mathrm{g} / \mathrm{mL}$ propidium iodide (Sigma-Aldrich, St. Louis, MO, USA) in PBS. Cells were resuspended in PBS, filtered through a $35 \mu \mathrm{m}$ cell strainer, and analyzed on a cell sorter (AriaII and FACS Diva). CellROX signal was detected in the APC channel (633 nm laser; 670/30 filter). Propidium iodide signal was detected in the PE-CF594 channel (561 nm laser; 600 LP, 610/20 filter). Samples were gated for cells (FSC-A vs. SSC-A), singlets (FSC-A vs. FSC-H, SSC-H vs. SSCW), and living cells (FSC-A vs. PE-CF594-A). Sorting was performed based on CellROX signal intensity (FSC-A vs. APC-A).

\subsection{Assessment of SFC Frequency}

For each sorted cell population (OXPHOS ${ }^{\text {low }}$, OXPHOShigh), 48 wells with 10 cells, 24 wells with 100 cells, and 16 wells with 1000 cells per well were sorted into 96-well ultra-low attachment plates (Corning, Corning, NY, USA) containing $100 \mu \mathrm{L}$ of culture medium ( $50 \%$ fresh, $50 \%$ conditioned (filtered medium of the bulk culture harvested during collection of cells)) supplemented with $100 \mu \mathrm{g} / \mathrm{mL}$ streptomycin and $100 \mathrm{U} / \mathrm{mL}$ penicillin per well. Fresh cytokines and medium were added every four days. Spheroid formation was analyzed 5-7 days after sorting using conventional light microscopy (Axiovert 40C, Zeiss, Oberkochen, Germany). Based on the fraction of spheroid-containing wells for each dilution, SFC frequencies were calculated using Poisson statistics and maximum likelihood (L-Calc, StemCell Technologies, Vancouver, BC, Canada). In vitro limiting dilution assays upon Mitotracker staining were performed three times for MMPlow and MMPhigh subpop- 
ulations of $\mathrm{P} 1$ and $\mathrm{P} 4$, twice for $\mathrm{P} 5$ as well as bulk (all living, i.e., $\mathrm{TOTO3}^{-}$cells) populations of P1 and P4, and once for P2 and P10.

\subsection{Assessment of TIC Frequency}

Mitotracker stained cells were sorted as described above, pelleted, resuspended in medium, and counted. Different cell counts were pelleted, resuspended in medium, mixed with matrigel (Corning, Corning, NY, USA), and injected subcutaneously into the flanks of immunodeficient NSG mice. For MMPlow as well as MMPhigh fractions of P1, four mice with $10^{6}$ cells, five mice with $10^{5}$ cells, six mice with $10^{4}$ cells, and six mice with $10^{3}$ cells were transplanted. For MMPlow as well as MMPhigh fractions of $\mathrm{P} 4$, three mice with $3 \times 10^{5}$ cells, four mice with $3 \times 10^{4}$ cells, 5-6 mice with $3 \times 10^{3}$ cells (six mice for $M M P^{\text {low }}$, five mice for $M M P^{\text {high }}$ ), 5-6 mice with $3 \times 10^{2}$ cells (five mice for $M M P^{\text {low }}$, six mice for $\mathrm{MMP}^{\text {high }}$ ), and six mice with $3 \times 10^{1}$ cells were transplanted. The experiments were performed blindly until observable tumor development.

Mice were monitored daily for tumor formation and sacrificed when tumors reached the maximum tolerable size or when experiments were ended (P1: seven weeks; P4: five weeks after transplantation). Based on the fraction of tumor formation for each dilution, TIC frequencies were calculated using Poisson statistics and maximum likelihood (L-Calc).

\subsection{Co-Cultivation Experiments}

Spheroid cultures $(n=3)$ were transduced with a lentiviral vector encoding for EGFP under control of the human PGK promoter at multiplicities of infection of 0.5 (P1, P4) or 1 (P5), yielding transduction efficiencies of $\sim 40-50 \%$. After expansion, cells were stained with Mitotracker and prepared for flow cytometry as described above. In addition to Mitotracker and TOTO-3, EGFP fluorescence was detected (488 nm laser; 505 LP, 525/50 filter). Cells were gated for low and high Mitotracker signal (MMPlow, MMPhigh) as well as for negative or positive EGFP signal $\left(\mathrm{EGFP}^{-}, \mathrm{EGFP}^{+}\right)$. For each culture, a set of $5 \times 10^{4}$ $\mathrm{MMP}^{\text {high }} \mathrm{EGFP}^{+}$and $5 \times 10^{4} \mathrm{MMPlow}^{\text {lowFP- }}$ cells as well as a set of $5 \times 10^{4} \mathrm{MMP}^{\text {high }} \mathrm{EGFP}^{-}$ and $5 \times 10^{4} \mathrm{MMP}^{\text {low }} \mathrm{EGFP}^{+}$cells were sorted simultaneously. To assess sorting efficiency, sorted samples were reanalyzed by recording 1000 living cells. Sorted cells were cultivated in 24-well ultra-low attachment plates (Corning, Corning, NY, USA). Spheroid formation and EGFP signal for each sample set were observed by fluorescence microscopy (Axiovert 200, Zeiss, Oberkochen, Germany). After 21 days in culture, cells were dissociated, stained with Mitotracker, and reanalyzed by flow cytometry as described.

\subsection{Inhibitor Treatments}

To assess SFC frequencies upon pretreatment with OXPHOS inhibitors, $5 \times 10^{5}$ tumor spheroid cells (P1, P4, P5) were seeded into two wells of 6-well ultra-low attachment plates (Corning, Corning, NY, USA). After seven days, $25 \mu \mathrm{M}$ CCCP or DMSO (SigmaAldrich, St. Louis, MO, USA) were added and cells were incubated for $4 \mathrm{~h}$ at $37^{\circ} \mathrm{C}$. Cells were dissociated, stained with $200 \mathrm{nM}$ TOTO-3 in PBS, and prepared for cell sorting as described. Living (i.e., TOTO-3-3 cells were sorted into 96-well ultra-low attachment plates containing $100 \mu \mathrm{L}$ of fresh culture medium supplemented with $100 \mu \mathrm{g} / \mathrm{mL}$ streptomycin and $100 \mathrm{U} / \mathrm{mL}$ penicillin per well. Limiting dilution and determination of SFC frequency were performed as described.

\subsection{Immunohistochemistry}

Formalin-fixed and paraffin-embedded tumor specimens of primary colorectal adenocarcinomas ( $n=25$ patients) and liver metastases ( $n=25$ patients) resected between 2013 and 2016 at the University Hospital Heidelberg were extracted from the archive of the Institute of Pathology, Heidelberg University, with the support of the tissue bank of the NCT (\#2831). Tissues were used in accordance with the ethical regulations of the tissue bank of the NCT defined by the local ethics committee. Diagnoses were made according 
to the recommendations of the World Health Organization classification of tumors of the digestive system [88].

Immunohistochemical staining was performed as previously described [89]. In brief, tissue sections were cut, pretreated with an antigen retrieval buffer, and stained for Ki-67, CA9, and LDH-A using an automatic staining device (Ventana Benchmark Ultra, Roche, Basel, Switzerland; Table S3).

\subsection{Mass Spectrometry}

Mass spectrometry was performed for $L G R 5^{+}$(i.e., $L G R 5$ score $>1$ ) patient-derived spheroid cultures $(n=4)$. Tumor spheroid cells were stained with Mitotracker, prepared for sorting as described, and $5 \times 10^{5}$ cells of $\mathrm{MMP}^{\text {low }}$ and $\mathrm{MMP}^{\text {high }}$ subfractions were sorted ( $n=3$ independent experiments). Cell pellets were reconstituted in $100 \mu \mathrm{L} 0.1 \%$ RapiGest SF Surfactant (Waters, Milford, MA, USA) in $100 \mathrm{mM}$ triethylammonium bicarbonate (Sigma-Aldrich, St. Louis, MO, USA) and $1 \times$ protease inhibitor cocktail (cOmplete, SigmaAldrich, St. Louis, MO, USA). Cells were lysed by probe-sonication twice for $15 \mathrm{~s}$ at $10 \%$ frequency, followed by centrifugation for $30 \mathrm{~min}$ at $15,000 \times g$ and $4{ }^{\circ} \mathrm{C} .10 \mu \mathrm{g}$ of protein per sample were denatured for $5 \mathrm{~min}$ at $95^{\circ} \mathrm{C}$, reduced with dithiothreitol (Biomol, Hamburg, Germany; $5 \mathrm{mM}$ final concentration) for $30 \mathrm{~min}$ at $60^{\circ} \mathrm{C}$, and alkylated with chloroacetamide (Sigma-Aldrich, St. Louis, MO, USA; $15 \mathrm{mM}$ final concentration) for 30 min at $23^{\circ} \mathrm{C}$. Proteins were digested overnight at $750 \mathrm{rpm}$ and $37^{\circ} \mathrm{C}$, at an enzyme/protein ratio of 1:20 with sequencing-grade modified trypsin (Promega, Madison, WI, USA) in double-distilled water $\left(\mathrm{ddH}_{2} \mathrm{O}\right)$. Samples were acidified by adding trifluoroacetic acid (Biosolve Chimie, Dieuze, France; $0.5 \%$ final concentration), incubated for another $30 \mathrm{~min}$ at $750 \mathrm{rpm}$ and $37^{\circ} \mathrm{C}$, and centrifuged for $30 \mathrm{~min}$ at $15,000 \times g$ and $23^{\circ} \mathrm{C}$.

Peptides were separated using the Easy NanoLC 1200 fitted with a trapping column (Acclaim PepMap C18, ThermoFisher, Waltham, MA, USA; $5 \mu \mathrm{m}, 100 \AA, 100 \mu \mathrm{m} \times 2 \mathrm{~cm}$ ) and an analytical column (nanoEase MZ BEH C18, Waters, Milford, MA, USA; $1.7 \mu \mathrm{m}$, $130 \AA, 75 \mu \mathrm{m} \times 25 \mathrm{~cm}$ ). The outlet of the analytical column was coupled directly to a Q-Exactive HF Orbitrap mass spectrometer (ThermoFisher, Waltham, MA, USA). Solvent A was $\mathrm{ddH}_{2} \mathrm{O}$ (Biosolve Chimie, Dieuze, France), $0.1 \%(v / v)$ formic acid (Biosolve Chimie, Dieuze, France) and solvent B was $80 \%$ acetonitrile (ThermoFisher, Waltham, MA, USA) in $\mathrm{ddH}_{2} \mathrm{O}, 0.1 \%(v / v)$ formic acid. Samples were loaded and peptides eluted with a $105 \mathrm{~min}$ gradient via the analytical column as described [90].

Raw files were processed using MaxQuant (https://www.maxquant.org; version 1.5.1.2) [91] against the human Uniprot database (20170801_Uniprot_homo-sapiens_canonical_reviewed; 20,214 entries) using the Andromeda search engine with the default search criteria: enzyme was set to trypsin/P with up to two missed cleavages. Carbamidomethylation $(\mathrm{C})$ and oxidation $(\mathrm{M})$ /acetylation (protein $\mathrm{N}$-term) were selected as fixed and variable modifications, respectively. Protein quantification was performed using the label-free quantification algorithm of MaxQuant. On top, intensity-based absolute quantification intensities were calculated with a log-fit enabled. Identification transfer between runs via the 'matching between runs' algorithm was allowed with a match time window of $0.3 \mathrm{~min}$. Peptide and protein hits were filtered at a false discovery rate of $1 \%$ with a minimal peptide length of seven amino acids. The reversed sequences of the target database were used as a decoy database. Proteins only identified by a modification site, contaminants, as well as reversed sequences were removed from the dataset.

Differential expression analysis was performed using limma moderated $t$ statistics $(\mathrm{R}$ package version 3.36.3; one-sample, two-sided) [92]. Here, data was first normalized based on median label-free quantification densities per sample. Next, ratios between MMPhigh and MMP ${ }^{\text {low }}$ cells were calculated. Significantly differentially expressed proteins were defined to show a Benjamini-Hochberg adjusted $p$-value $<0.05$ and an absolute $\log _{2}$-fold change $>1$. 


\subsection{Quantification and Statistical Analysis}

Statistical tests and sample size used for individual experiments are described in the corresponding figure legends or methods. The threshold for statistical significance was defined as $p<0.05$. Significance levels were denoted by asterisks: ${ }^{*} p<0.05$, ${ }^{* *} p<0.01$, ${ }_{* * * *} p<0.0001$. The threshold for statistical significance in univariable and multivariable survival analyses was defined as $p<0.1$.

\subsection{Data and Code Availability}

scRNA-seq data have been deposited at the European Genome-phenome Archive (EGA) which is hosted at the EBI and the CRG, under accession number EGAS00001004064. The mass spectrometry proteomics data have been deposited to the ProteomeXchange Consortium via the PRIDE [93] partner repository with the dataset identifier PXD018230.

Codes for analysis of scRNA-seq and RNA-FISH data are available at the github repository (https://github.com/eilslabs/CRC_scRNAseq).

\section{Conclusions}

In this study, we show at single-cell resolution that transcriptional heterogeneity identifies functional states during tumor-initiating cell differentiation in colorectal cancer. Targeting specific transcriptional states associated with cancer cell differentiation unravels novel potential vulnerabilities in human colorectal cancer.

Supplementary Materials: The following are available online at https:/ / www.mdpi.com/2072-669 4/13/5/1097/s1, Figure S1: Identification of heterogeneous gene expression programs, Figure S2: Cell cycle and proliferative activity of human colorectal cancer cells, Figure S3: Single-cell expression of representative stem and differentiation markers in patient-derived tumor models, Figure S4: Spatial localization in spheroid cultures in situ, Figure S5: Metabolic heterogeneity in colorectal tumors and patient-derived spheroids, Figure S6: Gating strategy for sorting according to mitochondrial membrane potential (MMP) using Mitotracker, Table S1: Signatures defined by non-negative matrix factorization (NNMF) of colorectal cancer spheroid single-cell RNA-sequencing data, Table S2: Univariable and multivariable survival models, Table S3: Antibodies for immunohistochemistry.

Author Contributions: Conceptualization, M.K.Z., S.M.T., S.M.D., R.E., H.G., C.C. and C.R.B.; formal analysis, M.K.Z., S.M.T., S.M.D., T.G.K., A.O., R.L.C., M.H., F.W.T., J.P., T.M., M.K. (Mathias Kalxdorf), M.K. (Mark Kriegsmann), K.K. and J.K.; investigation, M.K.Z., S.M.T., A.O., R.L.C., K.L., K.J. and T.M.; resources, M.S.; supervision, S.M.D., F.H., R.E., H.G., C.C. and C.R.B.; writing-original draft, M.K.Z., S.M.T., S.M.D., H.G., C.C. and C.R.B. All authors have read and agreed to the published version of the manuscript.

Funding: This research was funded by grants from the NCT Dresden (Translational Research Grants in Precision Oncology, TIC specific regulatory programs in GI cancers) to C.R.B., the NCT 3.0 Precision Oncology Program (NCT3.0_2015.4 TransOnco; NCT3.0_2015.54 DysregPT) to H.G., the EU Framework Program Horizon 2020 (TRANSCAN-2 ERA-NET, TACTIC consortium) to H.G., the Deutsche Krebshilfe Priority program 'Translational Oncology' (Colon-Resist-Net) to H.G. and C.R.B., the iMed Program (Helmholtz Association) to R.E., the BMBF-funded Heidelberg Center for Human Bioinformatics (HD-HuB) within the German Network for Bioinformatics Infrastructure (de.NBI; \#031A537A, \#031A537C) to R.E., and the Helmholtz Association (Incubator grant sparse2big; grant \#ZT-I-0007) to C.C.. DKFZ-HIPO provided technical support and funding through Grant No. HIPO-H012. S.M.T. and K.L. were recipients of the stipend for the PhD program of the Helmholtz International Graduate School for Cancer Research (DKFZ, Heidelberg). S.M.D. and T.G.K. were supported by a DKTK postdoctoral fellowship from the Heidelberg School of Oncology.

Institutional Review Board Statement: The study was conducted according to the guidelines of the Declaration of Helsinki, and approved by the University Ethics Review Board of Heidelberg University Hospital (323/2004 (19 May 2009) and S-649/2012 (7 June 2013)). All animal experimentation performed in this study was conducted according to national guidelines and was reviewed and confirmed by an institutional review board/ethics committee headed by the responsible animal welfare officer. The Regional Authority of Karlsruhe, Germany finally approved the animal experiments as 
the responsible national authority (approval numbers G228/12 (29 January 2013), G49/14 (26 June 2014), G233/15 (17 November 2015)).

Informed Consent Statement: Informed consent was obtained from all subjects involved in the study.

Data Availability Statement: scRNA-seq data have been deposited at the European Genomephenome Archive (EGA) which is hosted at the EBI and the CRG, under accession number EGAS00001004064. The mass spectrometry proteomics data have been deposited to the ProteomeXchange Consortium via the PRIDE [93] partner repository with the dataset identifier PXD018230. Codes for analysis of scRNA-seq and RNA-FISH data are available at the github repository (https://github.com/eilslabs/CRC_scRNAseq). Survival analysis was based on publicly available data generated by the TCGA Research Network: https:/ / www.cancer.gov/tcga.

Acknowledgments: The authors thank Nina Hofmann, Tim Kindinger, Sylvia Martin, Celine Reifenberg, and Christiane Zgorzelski for technical assistance. The authors thank the Central Animal Laboratory unit of the Center for Preclinical Research, DKFZ Heidelberg, for providing excellent services. The authors thank David Ibberson (CellNetworks Deep Sequencing Core Facility, Heidelberg University) for NGS services, Daniel Liber and Marizela Kulisic (TakaraBio, formerly Wafergen) for technical support for the iCELL8 system, and Henrik Kaessmann and his group (ZMBH, Heidelberg University) for support and helpful discussions regarding the iCELL8 system and single-cell analysis. The results shown here are in part based on data generated by the TCGA Research Network: https:/ / www.cancer.gov/tcga.

Conflicts of Interest: The authors declare no conflict of interest.

\section{References}

1. Jordan, C.T.; Guzman, M.L.; Noble, M. Cancer stem cells. N. Engl. J. Med. 2006, 355, 1253-1261. [CrossRef]

2. Reya, T.; Morrison, S.J.; Clarke, M.F.; Weissman, I.L. Stem cells, cancer, and cancer stem cells. Nature 2001, 414, 105-111. [CrossRef] [PubMed]

3. Visvader, J.E.; Lindeman, G.J. Cancer stem cells: Current status and evolving complexities. Cell Stem Cell 2012, 10, 717-728. [CrossRef]

4. Dieter, S.M.; Ball, C.R.; Hoffmann, C.M.; Nowrouzi, A.; Herbst, F.; Zavidij, O.; Abel, U.; Arens, A.; Weichert, W.; Brand, K.; et al. Distinct types of tumor-initiating cells form human colon cancer tumors and metastases. Cell Stem Cell 2011, 9, 357-365. [CrossRef]

5. Giessler, K.M.; Kleinheinz, K.; Huebschmann, D.; Balasubramanian, G.P.; Dubash, T.D.; Dieter, S.M.; Siegl, C.; Herbst, F.; Weber, S.; Hoffmann, C.M.; et al. Genetic subclone architecture of tumor clone-initiating cells in colorectal cancer. J. Exp. Med. 2017, 214, 2073-2088. [CrossRef]

6. Cortina, C.; Turon, G.; Stork, D.; Hernando-Momblona, X.; Sevillano, M.; Aguilera, M.; Tosi, S.; Merlos-Suárez, A.; Stephan-Otto Attolini, C.; Sancho, E.; et al. A genome editing approach to study cancer stem cells in human tumors. EMBO Mol. Med. 2017, 9, 869-879. [CrossRef]

7. Barker, N. Adult intestinal stem cells: Critical drivers of epithelial homeostasis and regeneration. Nat. Rev. Mol. Cell Biol. 2014, 15, 19-33. [CrossRef]

8. Merlos-Suárez, A.; Barriga, F.M.; Jung, P.; Iglesias, M.; Céspedes, M.V.; Rossell, D.; Sevillano, M.; Hernando-Momblona, X.; da Silva-Diz, V.; Muñoz, P.; et al. The intestinal stem cell signature identifies colorectal cancer stem cells and predicts disease relapse. Cell Stem Cell 2011, 8, 511-524. [CrossRef]

9. Bormann, F.; Rodríguez-Paredes, M.; Lasitschka, F.; Edelmann, D.; Musch, T.; Benner, A.; Bergman, Y.; Dieter, S.M.; Ball, C.R.; Glimm, H.; et al. Cell-of-Origin DNA Methylation Signatures Are Maintained during Colorectal Carcinogenesis. Cell Rep. 2018, 23, 3407-3418. [CrossRef]

10. Batlle, E.; Clevers, H. Cancer stem cells revisited. Nat. Med. 2017, 23, 1124-1134. [CrossRef]

11. Blanpain, C.; Fuchs, E. Stem cell plasticity. Plasticity of epithelial stem cells in tissue regeneration. Science 2014, $344,1242281$. [CrossRef]

12. Varga, J.; Greten, F.R. Cell plasticity in epithelial homeostasis and tumorigenesis. Nat. Cell Biol. 2017, 19, 1133-1141. [CrossRef]

13. De Sousa e Melo, F.; Kurtova, A.V.; Harnoss, J.M.; Kljavin, N.; Hoeck, J.D.; Hung, J.; Anderson, J.E.; Storm, E.E.; Modrusan, Z.; Koeppen, H.; et al. A distinct role for $\mathrm{Lgr5}^{+}$stem cells in primary and metastatic colon cancer. Nature 2017, 543, 676-680. [CrossRef]

14. Shimokawa, M.; Ohta, Y.; Nishikori, S.; Matano, M.; Takano, A.; Fujii, M.; Date, S.; Sugimoto, S.; Kanai, T.; Sato, T. Visualization and targeting of LGR5 ${ }^{+}$human colon cancer stem cells. Nature 2017, 545, 187-192. [CrossRef]

15. Ball, C.R.; Oppel, F.; Ehrenberg, K.R.; Dubash, T.D.; Dieter, S.M.; Hoffmann, C.M.; Abel, U.; Herbst, F.; Koch, M.; Werner, J.; et al. Succession of transiently active tumor-initiating cell clones in human pancreatic cancer xenografts. EMBO Mol. Med. 2017, 9, 918-932. [CrossRef] 
16. Dalerba, P.; Dylla, S.J.; Park, I.K.; Liu, R.; Wang, X.; Cho, R.W.; Hoey, T.; Gurney, A.; Huang, E.H.; Simeone, D.M.; et al. Phenotypic characterization of human colorectal cancer stem cells. Proc. Natl. Acad. Sci. USA 2007, 104, 10158-10163. [CrossRef]

17. Kreso, A.; O’Brien, C.A.; van Galen, P.; Gan, O.I.; Notta, F.; Brown, A.M.; Ng, K.; Ma, J.; Wienholds, E.; Dunant, C.; et al. Variable clonal repopulation dynamics influence chemotherapy response in colorectal cancer. Science 2013, 339, 543-548. [CrossRef] [PubMed]

18. Ricci-Vitiani, L.; Lombardi, D.G.; Pilozzi, E.; Biffoni, M.; Todaro, M.; Peschle, C.; De Maria, R. Identification and expansion of human colon-cancer-initiating cells. Nature 2007, 445, 111-115. [CrossRef]

19. Goldstein, L.D.; Chen, Y.J.; Dunne, J.; Mir, A.; Hubschle, H.; Guillory, J.; Yuan, W.; Zhang, J.; Stinson, J.; Jaiswal, B.; et al. Massively parallel nanowell-based single-cell gene expression profiling. BMC Genom. 2017, 18, 519. [CrossRef]

20. Butler, A.; Hoffman, P.; Smibert, P.; Papalexi, E.; Satija, R. Integrating single-cell transcriptomic data across different conditions, technologies, and species. Nat. Biotechnol. 2018, 36, 411-420. [CrossRef]

21. Tirosh, I.; Izar, B.; Prakadan, S.M.; Wadsworth, M.H., 2nd; Treacy, D.; Trombetta, J.J.; Rotem, A.; Rodman, C.; Lian, C.; Murphy, G.; et al. Dissecting the multicellular ecosystem of metastatic melanoma by single-cell RNA-seq. Science 2016, 352, 189-196. [CrossRef]

22. Tirosh, I.; Venteicher, A.S.; Hebert, C.; Escalante, L.E.; Patel, A.P.; Yizhak, K.; Fisher, J.M.; Rodman, C.; Mount, C.; Filbin, M.G.; et al. Single-cell RNA-seq supports a developmental hierarchy in human oligodendroglioma. Nature 2016, 539, 309-313. [CrossRef]

23. Rodríguez-Colman, M.J.; Schewe, M.; Meerlo, M.; Stigter, E.; Gerrits, J.; Pras-Raves, M.; Sacchetti, A.; Hornsveld, M.; Oost, K.C.; Snippert, H.J.; et al. Interplay between metabolic identities in the intestinal crypt supports stem cell function. Nature 2017, 543, 424-427. [CrossRef]

24. Lee, D.D.; Seung, H.S. Learning the parts of objects by non-negative matrix factorization. Nature 1999, 401, 788-791. [CrossRef] [PubMed]

25. Puram, S.V.; Tirosh, I.; Parikh, A.S.; Patel, A.P.; Yizhak, K.; Gillespie, S.; Rodman, C.; Luo, C.L.; Mroz, E.A.; Emerick, K.S.; et al. Single-Cell Transcriptomic Analysis of Primary and Metastatic Tumor Ecosystems in Head and Neck Cancer. Cell 2017, 171, 1611-1624.e1624. [CrossRef] [PubMed]

26. Barker, N.; Ridgway, R.A.; van Es, J.H.; van de Wetering, M.; Begthel, H.; van den Born, M.; Danenberg, E.; Clarke, A.R.; Sansom, O.J.; Clevers, H. Crypt stem cells as the cells-of-origin of intestinal cancer. Nature 2009, 457, 608-611. [CrossRef] [PubMed]

27. Barker, N.; van Es, J.H.; Kuipers, J.; Kujala, P.; van den Born, M.; Cozijnsen, M.; Haegebarth, A.; Korving, J.; Begthel, H.; Peters, P.J.; et al. Identification of stem cells in small intestine and colon by marker gene Lgr5. Nature 2007, 449, 1003-1007. [CrossRef]

28. Cancer Genome Atlas, N. Comprehensive molecular characterization of human colon and rectal cancer. Nature 2012, 487, 330-337. [CrossRef]

29. Eide, P.W.; Bruun, J.; Lothe, R.A.; Sveen, A. CMScaller: An R package for consensus molecular subtyping of colorectal cancer pre-clinical models. Sci. Rep. 2017, 7, 16618. [CrossRef]

30. Guinney, J.; Dienstmann, R.; Wang, X.; de Reyniès, A.; Schlicker, A.; Soneson, C.; Marisa, L.; Roepman, P.; Nyamundanda, G.; Angelino, P.; et al. The consensus molecular subtypes of colorectal cancer. Nat. Med. 2015, 21, 1350-1356. [CrossRef]

31. Li, H.; Courtois, E.T.; Sengupta, D.; Tan, Y.; Chen, K.H.; Goh, J.J.L.; Kong, S.L.; Chua, C.; Hon, L.K.; Tan, W.S.; et al. Reference component analysis of single-cell transcriptomes elucidates cellular heterogeneity in human colorectal tumors. Nat. Genet. 2017, 49, 708-718. [CrossRef]

32. Falkowska-Hansen, B.; Kollar, J.; Grüner, B.M.; Schanz, M.; Boukamp, P.; Siveke, J.; Rethwilm, A.; Kirschner, M. An inducible Tet-Off-H2B-GFP lentiviral reporter vector for detection and in vivo isolation of label-retaining cells. Exp. Cell Res. 2010, 316, 1885-1895. [CrossRef]

33. Haegebarth, A.; Clevers, H. Wnt signaling, lgr5, and stem cells in the intestine and skin. Am. J. Pathol. 2009, 174, 715-721. [CrossRef]

34. Oliver, P.L.; Finelli, M.J.; Edwards, B.; Bitoun, E.; Butts, D.L.; Becker, E.B.; Cheeseman, M.T.; Davies, B.; Davies, K.E. Oxr1 is essential for protection against oxidative stress-induced neurodegeneration. PLoS Genet. 2011, 7, e1002338. [CrossRef]

35. Li, W.; Kennedy, D.; Shao, Z.; Wang, X.; Kamdar, A.K.; Weber, M.; Mislick, K.; Kiefer, K.; Morales, R.; Agatisa-Boyle, B.; et al. Paraoxonase 2 prevents the development of heart failure. Free Radic. Biol. Med. 2018, 121, 117-126. [CrossRef] [PubMed]

36. Kaur, R.; Liu, X.; Gjoerup, O.; Zhang, A.; Yuan, X.; Balk, S.P.; Schneider, M.C.; Lu, M.L. Activation of p21-activated kinase 6 by MAP kinase kinase 6 and p38 MAP kinase. J. Biol. Chem. 2005, 280, 3323-3330. [CrossRef]

37. Klein, A.M.; Mazutis, L.; Akartuna, I.; Tallapragada, N.; Veres, A.; Li, V.; Peshkin, L.; Weitz, D.A.; Kirschner, M.W. Droplet barcoding for single-cell transcriptomics applied to embryonic stem cells. Cell 2015, 161, 1187-1201. [CrossRef]

38. Macosko, E.Z.; Basu, A.; Satija, R.; Nemesh, J.; Shekhar, K.; Goldman, M.; Tirosh, I.; Bialas, A.R.; Kamitaki, N.; Martersteck, E.M.; et al. Highly Parallel Genome-wide Expression Profiling of Individual Cells Using Nanoliter Droplets. Cell 2015, 161, 1202-1214. [CrossRef] [PubMed]

39. Sasaki, N.; Sachs, N.; Wiebrands, K.; Ellenbroek, S.I.; Fumagalli, A.; Lyubimova, A.; Begthel, H.; van den Born, M.; van Es, J.H.;

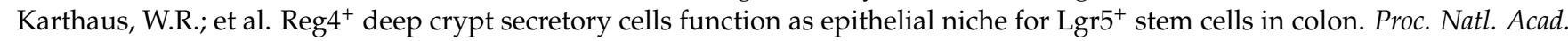
Sci. USA 2016, 113, E5399-E5407. [CrossRef]

40. Baker, A.M.; Graham, T.A.; Elia, G.; Wright, N.A.; Rodriguez-Justo, M. Characterization of LGR5 stem cells in colorectal adenomas and carcinomas. Sci. Rep. 2015, 5, 8654. [CrossRef] 
41. Sato, T.; van Es, J.H.; Snippert, H.J.; Stange, D.E.; Vries, R.G.; van den Born, M.; Barker, N.; Shroyer, N.F.; van de Wetering, M.; Clevers, H. Paneth cells constitute the niche for Lgr5 stem cells in intestinal crypts. Nature 2011, 469, 415-418. [CrossRef]

42. Dalerba, P.; Kalisky, T.; Sahoo, D.; Rajendran, P.S.; Rothenberg, M.E.; Leyrat, A.A.; Sim, S.; Okamoto, J.; Johnston, D.M.; Qian, D.; et al. Single-cell dissection of transcriptional heterogeneity in human colon tumors. Nat. Biotechnol. 2011, 29, 1120-1127. [CrossRef]

43. Tirier, S.M.; Park, J.; Preußer, F.; Amrhein, L.; Gu, Z.; Steiger, S.; Mallm, J.P.; Krieger, T.; Waschow, M.; Eismann, B.; et al. Pheno-seq-linking visual features and gene expression in 3D cell culture systems. Sci. Rep. 2019, 9, 12367. [CrossRef]

44. Heytler, P.G.; Prichard, W.W. A new class of uncoupling agents-carbonyl cyanide phenylhydrazones. Biochem. Biophys. Res. Commun. 1962, 7, 272-275. [CrossRef]

45. Joung, J.G.; Oh, B.Y.; Hong, H.K.; Al-Khalidi, H.; Al-Alem, F.; Lee, H.O.; Bae, J.S.; Kim, J.; Cha, H.U.; Alotaibi, M.; et al. Tumor Heterogeneity Predicts Metastatic Potential in Colorectal Cancer. Clin. Cancer Res. Off. J. Am. Assoc. Cancer Res. 2017, 23, 7209-7216. [CrossRef]

46. Yan, K.S.; Janda, C.Y.; Chang, J.; Zheng, G.X.Y.; Larkin, K.A.; Luca, V.C.; Chia, L.A.; Mah, A.T.; Han, A.; Terry, J.M.; et al. Non-equivalence of Wnt and R-spondin ligands during Lgr5 ${ }^{+}$intestinal stem-cell self-renewal. Nature 2017, 545, $238-242$. [CrossRef]

47. Dieter, S.M.; Glimm, H.; Ball, C.R. Colorectal cancer-initiating cells caught in the act. EMBO Mol. Med. 2017, 9, 856-858. [CrossRef]

48. Puig, I.; Tenbaum, S.P.; Chicote, I.; Arqués, O.; Martínez-Quintanilla, J.; Cuesta-Borrás, E.; Ramírez, L.; Gonzalo, P.; Soto, A.; Aguilar, S.; et al. TET2 controls chemoresistant slow-cycling cancer cell survival and tumor recurrence. J. Clin. Investig. 2018, 128, 3887-3905. [CrossRef] [PubMed]

49. Ayyaz, A.; Kumar, S.; Sangiorgi, B.; Ghoshal, B.; Gosio, J.; Ouladan, S.; Fink, M.; Barutcu, S.; Trcka, D.; Shen, J.; et al. Single-cell transcriptomes of the regenerating intestine reveal a revival stem cell. Nature 2019, 569, 121-125. [CrossRef]

50. Grün, D.; Lyubimova, A.; Kester, L.; Wiebrands, K.; Basak, O.; Sasaki, N.; Clevers, H.; van Oudenaarden, A. Single-cell messenger RNA sequencing reveals rare intestinal cell types. Nature 2015, 525, 251-255. [CrossRef]

51. Yan, K.S.; Gevaert, O.; Zheng, G.X.Y.; Anchang, B.; Probert, C.S.; Larkin, K.A.; Davies, P.S.; Cheng, Z.F.; Kaddis, J.S.; Han, A.; et al. Intestinal Enteroendocrine Lineage Cells Possess Homeostatic and Injury-Inducible Stem Cell Activity. Cell Stem Cell 2017, 21, 78-90.e76. [CrossRef]

52. Haber, A.L.; Biton, M.; Rogel, N.; Herbst, R.H.; Shekhar, K.; Smillie, C.; Burgin, G.; Delorey, T.M.; Howitt, M.R.; Katz, Y.; et al. A single-cell survey of the small intestinal epithelium. Nature 2017, 551, 333-339. [CrossRef]

53. Chen, E.C.; Karl, T.A.; Kalisky, T.; Gupta, S.K.; O’Brien, C.A.; Longacre, T.A.; van de Rijn, M.; Quake, S.R.; Clarke, M.F.; Rothenberg, M.E. KIT Signaling Promotes Growth of Colon Xenograft Tumors in Mice and Is Up-Regulated in a Subset of Human Colon Cancers. Gastroenterology 2015, 149, 705-717.e702. [CrossRef]

54. Patel, A.P.; Tirosh, I.; Trombetta, J.J.; Shalek, A.K.; Gillespie, S.M.; Wakimoto, H.; Cahill, D.P.; Nahed, B.V.; Curry, W.T.; Martuza, R.L.; et al. Single-cell RNA-seq highlights intratumoral heterogeneity in primary glioblastoma. Science 2014, 344, 1396-1401. [CrossRef]

55. Biton, M.; Haber, A.L.; Rogel, N.; Burgin, G.; Beyaz, S.; Schnell, A.; Ashenberg, O.; Su, C.W.; Smillie, C.; Shekhar, K.; et al. T Helper Cell Cytokines Modulate Intestinal Stem Cell Renewal and Differentiation. Cell 2018, 175, 1307-1320.e1322. [CrossRef]

56. Velten, L.; Haas, S.F.; Raffel, S.; Blaszkiewicz, S.; Islam, S.; Hennig, B.P.; Hirche, C.; Lutz, C.; Buss, E.C.; Nowak, D.; et al. Human haematopoietic stem cell lineage commitment is a continuous process. Nat. Cell Biol. 2017, 19, 271-281. [CrossRef] [PubMed]

57. Fumagalli, A.; Oost, K.C.; Kester, L.; Morgner, J.; Bornes, L.; Bruens, L.; Spaargaren, L.; Azkanaz, M.; Schelfhorst, T.; Beerling, E.; et al. Plasticity of Lgr5-Negative Cancer Cells Drives Metastasis in Colorectal Cancer. Cell Stem Cell 2020, 26, 569-578.e567. [CrossRef] [PubMed]

58. Morral, C.; Stanisavljevic, J.; Hernando-Momblona, X.; Mereu, E.; Álvarez-Varela, A.; Cortina, C.; Stork, D.; Slebe, F.; Turon, G.; Whissell, G.; et al. Zonation of Ribosomal DNA Transcription Defines a Stem Cell Hierarchy in Colorectal Cancer. Cell Stem Cell 2020, 26, 845-861 e812. [CrossRef]

59. Zheng, J. Energy metabolism of cancer: Glycolysis versus oxidative phosphorylation (Review). Oncol. Lett. 2012, 4, 1151-1157. [CrossRef] [PubMed]

60. Song, K.; Kwon, H.; Han, C.; Zhang, J.; Dash, S.; Lim, K.; Wu, T. Active glycolytic metabolism in CD133(+) hepatocellular cancer stem cells: Regulation by MIR-122. Oncotarget 2015, 6, 40822-40835. [CrossRef] [PubMed]

61. Feng, W.; Gentles, A.; Nair, R.V.; Huang, M.; Lin, Y.; Lee, C.Y.; Cai, S.; Scheeren, F.A.; Kuo, A.H.; Diehn, M. Targeting unique metabolic properties of breast tumor initiating cells. Stem Cells 2014, 32, 1734-1745. [CrossRef]

62. Palorini, R.; Votta, G.; Balestrieri, C.; Monestiroli, A.; Olivieri, S.; Vento, R.; Chiaradonna, F. Energy metabolism characterization of a novel cancer stem cell-like line 3AB-OS. J. Cell. Biochem. 2014, 115, 368-379. [CrossRef]

63. Shen, Y.A.; Lin, C.H.; Chi, W.H.; Wang, C.Y.; Hsieh, Y.T.; Wei, Y.H.; Chen, Y.J. Resveratrol Impedes the Stemness, EpithelialMesenchymal Transition, and Metabolic Reprogramming of Cancer Stem Cells in Nasopharyngeal Carcinoma through p53 Activation. Evid.-Based Complementary Altern. Med. ECAM 2013, 2013, 590393. [CrossRef]

64. Viale, A.; Pettazzoni, P.; Lyssiotis, C.A.; Ying, H.; Sánchez, N.; Marchesini, M.; Carugo, A.; Green, T.; Seth, S.; Giuliani, V.; et al. Oncogene ablation-resistant pancreatic cancer cells depend on mitochondrial function. Nature 2014, 514, 628-632. [CrossRef] 
65. Janiszewska, M.; Suvà, M.L.; Riggi, N.; Houtkooper, R.H.; Auwerx, J.; Clément-Schatlo, V.; Radovanovic, I.; Rheinbay, E.; Provero, P.; Stamenkovic, I. Imp2 controls oxidative phosphorylation and is crucial for preserving glioblastoma cancer stem cells. Genes Dev. 2012, 26, 1926-1944. [CrossRef]

66. Lagadinou, E.D.; Sach, A.; Callahan, K.; Rossi, R.M.; Neering, S.J.; Minhajuddin, M.; Ashton, J.M.; Pei, S.; Grose, V.; O’Dwyer, K.M.; et al. BCL-2 inhibition targets oxidative phosphorylation and selectively eradicates quiescent human leukemia stem cells. Cell Stem Cell 2013, 12, 329-341. [CrossRef]

67. Elgendy, M.; Cirò, M.; Hosseini, A.; Weiszmann, J.; Mazzarella, L.; Ferrari, E.; Cazzoli, R.; Curigliano, G.; DeCensi, A.; Bonanni, B.; et al. Combination of Hypoglycemia and Metformin Impairs Tumor Metabolic Plasticity and Growth by Modulating the PP2A-GSK3 $3-M C L-1$ Axis. Cancer Cell 2019, 35, 798-815.e795. [CrossRef]

68. Wiener, Z.; Högström, J.; Hyvönen, V.; Band, A.M.; Kallio, P.; Holopainen, T.; Dufva, O.; Haglund, C.; Kruuna, O.; Oliver, G.; et al. Prox1 promotes expansion of the colorectal cancer stem cell population to fuel tumor growth and ischemia resistance. Cell Rep. 2014, 8, 1943-1956. [CrossRef] [PubMed]

69. Ragusa, S.; Cheng, J.; Ivanov, K.I.; Zangger, N.; Ceteci, F.; Bernier-Latmani, J.; Milatos, S.; Joseph, J.M.; Tercier, S.; Bouzourene, H.; et al. PROX1 promotes metabolic adaptation and fuels outgrowth of Wnt(high) metastatic colon cancer cells. Cell Rep. 2014, 8, 1957-1973. [CrossRef] [PubMed]

70. Jeong, D.; Kim, H.; Kim, D.; Ban, S.; Oh, S.; Ji, S.; Kang, D.; Lee, H.; Ahn, T.S.; Kim, H.J.; et al. Defensin alpha 6 (DEFA6) is a prognostic marker in colorectal cancer. Cancer Biomark. Sect. A Dis. Markers 2019, 24, 485-495. [CrossRef] [PubMed]

71. Rothenberg, M.E.; Nusse, Y.; Kalisky, T.; Lee, J.J.; Dalerba, P.; Scheeren, F.; Lobo, N.; Kulkarni, S.; Sim, S.; Qian, D.; et al. Identification of a cKit ${ }^{+}$colonic crypt base secretory cell that supports Lgr5 ${ }^{+}$stem cells in mice. Gastroenterology 2012, 142, 1195-1205 e1196. [CrossRef] [PubMed]

72. Altmann, G.G. Morphological observations on mucus-secreting nongoblet cells in the deep crypts of the rat ascending colon. Am. J. Anat. 1983, 167, 95-117. [CrossRef]

73. Dieter, S.M.; Giessler, K.M.; Kriegsmann, M.; Dubash, T.D.; Möhrmann, L.; Schulz, E.R.; Siegl, C.; Weber, S.; Strakerjahn, H.; Oberlack, A.; et al. Patient-derived xenografts of gastrointestinal cancers are susceptible to rapid and delayed B-lymphoproliferation. Int. J. Cancer 2017, 140, 1356-1363. [CrossRef]

74. Dubash, T.D.; Hoffmann, C.M.; Oppel, F.; Giessler, K.M.; Weber, S.; Dieter, S.M.; Hüllein, J.; Zenz, T.; Herbst, F.; Scholl, C.; et al. Phenotypic differentiation does not affect tumorigenicity of primary human colon cancer initiating cells. Cancer Lett. 2016, 371, 326-333. [CrossRef] [PubMed]

75. Riffle, S.; Hegde, R.S. Modeling tumor cell adaptations to hypoxia in multicellular tumor spheroids. J. Exp. Clin. Cancer Res. 2017, 36, 102. [CrossRef] [PubMed]

76. Fujii, M.; Shimokawa, M.; Date, S.; Takano, A.; Matano, M.; Nanki, K.; Ohta, Y.; Toshimitsu, K.; Nakazato, Y.; Kawasaki, K.; et al. A Colorectal Tumor Organoid Library Demonstrates Progressive Loss of Niche Factor Requirements during Tumorigenesis. Cell Stem Cell 2016, 18, 827-838. [CrossRef]

77. Van de Wetering, M.; Francies, H.E.; Francis, J.M.; Bounova, G.; Iorio, F.; Pronk, A.; van Houdt, W.; van Gorp, J.; Taylor-Weiner, A.; Kester, L.; et al. Prospective derivation of a living organoid biobank of colorectal cancer patients. Cell 2015, 161, 933-945. [CrossRef]

78. Sato, T.; Stange, D.E.; Ferrante, M.; Vries, R.G.; Van Es, J.H.; Van den Brink, S.; Van Houdt, W.J.; Pronk, A.; Van Gorp, J.; Siersema, P.D.; et al. Long-term expansion of epithelial organoids from human colon, adenoma, adenocarcinoma, and Barrett's epithelium. Gastroenterology 2011, 141, 1762-1772. [CrossRef]

79. Li, Y.; Liu, Y.; Liu, B.; Wang, J.; Wei, S.; Qi, Z.; Wang, S.; Fu, W.; Chen, Y.G. A growth factor-free culture system underscores the coordination between Wnt and BMP signaling in Lgr5 ${ }^{+}$intestinal stem cell maintenance. Cell Discov. 2018, 4, 49. [CrossRef] [PubMed]

80. Castro, F.; Dirks, W.G.; Fähnrich, S.; Hotz-Wagenblatt, A.; Pawlita, M.; Schmitt, M. High-throughput SNP-based authentication of human cell lines. Int. J. Cancer 2013, 132, 308-314. [CrossRef]

81. Schmitt, M.; Pawlita, M. High-throughput detection and multiplex identification of cell contaminations. Nucleic Acids Res. 2009, 37, e119. [CrossRef]

82. Girardot, C.; Scholtalbers, J.; Sauer, S.; Su, S.Y.; Furlong, E.E. Je, a versatile suite to handle multiplexed NGS libraries with unique molecular identifiers. BMC Bioinform. 2016, 17, 419. [CrossRef]

83. Subramanian, A.; Tamayo, P.; Mootha, V.K.; Mukherjee, S.; Ebert, B.L.; Gillette, M.A.; Paulovich, A.; Pomeroy, S.L.; Golub, T.R.; Lander, E.S.; et al. Gene set enrichment analysis: A knowledge-based approach for interpreting genome-wide expression profiles. Proc. Natl. Acad. Sci. USA 2005, 102, 15545-15550. [CrossRef]

84. Wu, Z.; Wu, Z. Exploration, visualization, and preprocessing of high-dimensional data. Methods Mol. Biol. 2010, 620, 267-284. [CrossRef] [PubMed]

85. Stuart, T.; Butler, A.; Hoffman, P.; Hafemeister, C.; Papalexi, E.; Mauck, W.M., 3rd; Hao, Y.; Stoeckius, M.; Smibert, P.; Satija, R. Comprehensive Integration of Single-Cell Data. Cell 2019, 177, 1888-1902 e1821. [CrossRef]

86. He, K.; Gkioxari, G.; Dollár, P.; Girshick, R. Mask r-cnn. In Proceedings of the IEEE International Conference on Computer Vision, Venice, Italy, 22-29 October 2017; pp. 2980-2988.

87. Lin, T.-Y.; Maire, M.; Belongie, S.; Hays, J.; Perona, P.; Ramanan, D.; Dollár, P.; Zitnick, C.L. Microsoft coco: Common objects in context. In Proceedings of the European Conference on Computer Vision, Zurich, Switzerland, 6-12 September 2014; pp. 740-755. 
88. Baretton, G. Pathology of the lower gastrointestinal tract. Der Pathol. 2011, 32, 273-274. [CrossRef]

89. Kriegsmann, K.; Cremer, M.; Zgorzelski, C.; Harms, A.; Muley, T.; Winter, H.; Kazdal, D.; Warth, A.; Kriegsmann, M. Agreement of CK5/6, p40, and p63 immunoreactivity in non-small cell lung cancer. Pathology 2019, 51, 240-245. [CrossRef]

90. Erich, K.; Reinle, K.; Müller, T.; Munteanu, B.; Sammour, D.A.; Hinsenkamp, I.; Gutting, T.; Burgermeister, E.; Findeisen, P.; Ebert, M.P.; et al. Spatial Distribution of Endogenous Tissue Protease Activity in Gastric Carcinoma Mapped by MALDI Mass Spectrometry Imaging. Mol. Cell. Proteom. MCP 2019, 18, 151-161. [CrossRef] [PubMed]

91. Cox, J.; Mann, M. MaxQuant enables high peptide identification rates, individualized p.p.b.-range mass accuracies and proteomewide protein quantification. Nat. Biotechnol. 2008, 26, 1367-1372. [CrossRef] [PubMed]

92. Ritchie, M.E.; Phipson, B.; Wu, D.; Hu, Y.; Law, C.W.; Shi, W.; Smyth, G.K. limma powers differential expression analyses for RNA-sequencing and microarray studies. Nucleic Acids Res. 2015, 43, e47. [CrossRef] [PubMed]

93. Perez-Riverol, Y.; Csordas, A.; Bai, J.; Bernal-Llinares, M.; Hewapathirana, S.; Kundu, D.J.; Inuganti, A.; Griss, J.; Mayer, G.; Eisenacher, M.; et al. The PRIDE database and related tools and resources in 2019: Improving support for quantification data. Nucleic Acids Res. 2019, 47, D442-D450. [CrossRef] [PubMed] 